Research Article

\title{
Verification of Energy Usage Based on Standard Building Model Development of Low-Rise Residential Buildings in South Korea
}

\author{
KyungSoo Kim $\mathbb{D}^{1},{ }^{1}$ DongChul Yoo, ${ }^{2}$ ChangHo Choi, ${ }^{2}$ and HyangIn Jang ${ }^{1}$ \\ ${ }^{1}$ Institute of Green Building and New Technology, Mirae Environment Plan Architects, Seoul, Republic of Korea \\ ${ }^{2}$ Department of Architectural Engineering, Kwangwoon University, Seoul, Republic of Korea \\ Correspondence should be addressed to HyangIn Jang; energyopt@naver.com
}

Received 13 October 2020; Revised 15 March 2021; Accepted 22 March 2021; Published 20 April 2021

Academic Editor: Payam Shafigh

Copyright $\left({ }_{0} 2021\right.$ KyungSoo Kim et al. This is an open access article distributed under the Creative Commons Attribution License, which permits unrestricted use, distribution, and reproduction in any medium, provided the original work is properly cited.

The energy consumption of low-rise residential buildings in South Korea exceeds the targets set in national policies and the standards of other countries. Moreover, there are insufficient policies in place to improve the energy performance of existing lowrise residential buildings and no means to investigate the current status. A standard model enables cost-effective and fast load forecasting and can also be used to establish long-term policies through evaluation of energy saving in buildings before and after the application of energy policies. This study developed a standard model for predicting energy consumption by reflecting the characteristics of low-rise residential buildings in Korea. The standard model was developed based on reliable related standards, national statistical data, and national reports, and the energy variables applied were validated through a sensitivity analysis. Surveys and field measurements were conducted to investigate the energy usage of 70 households in low-rise residential buildings in Korea, and the developed model was validated through comparison with the actual energy usage data. Consequently, the total energy consumption error rate was $12.67 \%$ ( $R^{2}$ value: 0.8164$)$, with a significance level higher than $80 \%$, which indicated that the developed model was highly efficient and reliable.

\section{Introduction}

According to the Fifth Climate Change Assessment Report of the United Nation's Intergovernmental Panel on Climate Change (IPCC 2014), global greenhouse gas (GHG) emissions must be reduced by up to $70 \%$ by 2050 -compared to the levels in 2010 -in order to decrease the global average temperature by $2^{\circ} \mathrm{C}$. This is the goal of the Paris Agreement for a new climate regime in preparation for industrialization by the end of the 21st century [1]. Currently, the building sector consumes $30 \%-40 \%$ of the world's energy [2-4], with $45 \%-65 \%$ of solid waste that negatively affects the environment [5-7]. Reportedly, this accounts for approximately $40 \%$ of carbon dioxide emissions [8-14]. As of 2019, the total energy consumption in Korea was $231235 \mathrm{GWh}$, of which approximately $19.9 \%(45952 \mathrm{GWh})$ was accounted for by the building sector [15]. Within the building sector, residential buildings (single housing, multifamily housing, etc.) have been reported to account for $58.3 \%$ of energy use.
As of 2016, the Republic of Korea has ranked fifth among the Organization for Economic Co-operation and Development (OECD) member countries with excessive GHG emissions, producing 700 million tons of GHGs annually. Therefore, in order to reduce Korea's GHG emissions to 536 million tons by 2030, the Korean government raised its GHG reduction rate to $32.5 \%$ ( $25.7 \%$ of the reduction target in Korea in 2016). In particular, the GHG reduction rate in the building sector has been raised from $18.1 \%$ (2016) to $32.7 \%$ (2018). Moreover, the demand for improved energy performance in the building sector is increasing in Korea [16-19]. Owing to the abundance of old houses with low insulation performance, residential buildings in Korea consume a high amount of energy per building area (358 $\mathrm{kWh} / \mathrm{m}^{2}$ ), which has been reported to be far above Korea's national building energy policy and even other countries' standards [20-22]. According to the building energy efficiency certification system in Korea, the energy consumption criterion for Level 1 residential buildings is 
$120-150 \mathrm{kWh} / \mathrm{m}^{2}$. Therefore, residential buildings in Korea consume approximately thrice the energy set by this standard. In Korea, most low-rise residential buildings were erected prior to industrialization; in fact, over $75 \%$ of these buildings were completed before 2001 (under the Republic of Korea Building Act, low-rise residential areas are classified as detached, multifamily, and row houses). Korea's insulation standard was also set before 2001, and the heat transmission rate of the outer walls of a building has been reported to be $1.047 \mathrm{~W} / \mathrm{m}^{2} \mathrm{~K}$, which is approximately six times of the $0.170 \mathrm{~W} / \mathrm{m}^{2} \mathrm{~K}$ standard revised in 2019 . Thus, the level of energy performance in Korea's low-rise residential areas is thought to be poor.

To solve this problem, the energy consumption of existing buildings must be urgently reduced while also establishing environmental regulations for energy emissions [23]. However, Korea currently lacks policies to improve the energy performance of its existing low-rise residential buildings, and there are no means by which to investigate the current status. As such, the results and situations vary depending on the data and values used by relevant experts. In order to improve the energy performance of existing buildings, their energy efficiency and load must be assessed rapidly and cost-effectively using standard models [24-26] In particular, the effects of building energy conservation before and after energy policy implementation can be assessed and used as a set of criteria to determine long-term policies. However, because Korea does not currently have a standard model for low-rise residential buildings, it has been impossible to predict loads quickly. Developing a standard model that reflects the characteristics of Korean low-rise buildings and validating it by using reliable national statistics data and actual energy usage data will allow us to evaluate the measures and effects of building energy-saving policies in Korea. It can also be used as a reference for establishing energy policy regulations, and the expansion of its application will improve the energy performance of low-rise residential buildings in Korea [27].

Therefore, this study developed the energy variables of a standard model for predicting the energy consumption of low-rise residential buildings in Korea and verified these variables through sensitivity analysis. Surveys and field measurements were conducted to investigate the energy usage of low-rise residential buildings. The developed standard model was validated based on national energy statistics and collected energy usage data. This study was conducted only in central Korea, where $67 \%$ of the country's population resides.

Figure 1 shows the schematic representation of the methodology used in this study, and the details are as follows. First, the energy variables of the standard model were selected by defining the variables that affect building energy consumption by considering international standards and standard model variables. The variables from Korean legal standards, literature, and statistical data were used as energy variables of the standard model. Second, the statistical data of the state and public institutions in Korea were used as input data for energy variables, but some items that were difficult to collect used the proposed values based on reliable data from the literature review. Third, a sensitivity analysis based on the simulation analysis results was performed to validate the energy variables, and the ones that affected energy consumption were used in the final standard model. Fourth, the standard model was validated by selecting 70 households from low-rise residential areas in Korea by population sampling, establishing the data values and energy usage of the variables through field measurements and surveys, and investigating energy usage statistics published by public institutions in Korea. Fifth, the collected data and the standard model simulation results were verified based on the national energy statistics data to confirm whether the values were distributed within the collected statistical range. Sixth, the standard model was validated by comparing the energy usage data collected through field measurements and the energy consumption of the standard model according to the variables.

\subsection{Consideration of Methodologies to Develop Standard} Models. Many academic research institutes worldwide are conducting studies to define and improve the accuracy of standard models by collecting various building data. The National Renewable Energy Laboratory (NREL) conducted a study on the development of standard or reference energy models for the most common commercial buildings to serve as a starting point for energy efficiency research [28], and Kim (2018) defined standard model variables for commercial buildings using the statistical data of Korea [29]. Furthermore, studies were performed to improve the accuracy of standard models by conducting literature review by using public databases [30, 31]. Standard models are usually developed using either credible state agencies and public statistical data or building standards, findings of previous studies, and experience of experts. Internationally recognized standard models developed by the former method are reliable and applicable in various areas, but those developed by the latter method have limited application if the data and consensus procedures lack public confidence. Therefore, reliable public data should be used to establish valid variables and input data in the development of standard models.

\subsection{Consideration of International Standard Model Variables.}

In order to develop specific energy variables for our standard model, we considered the standard model provided by the American Society of Heating, Refrigerating and Air-Conditioning Engineers (ASHRAE) and the building performance variables of EN ISO 52016. The ASHRAE Standard 90.1 was used to develop a prototype supporting the United States Department of Energy's Building Energy Codes Program [32, 33], which, in turn, provided standards for 16 building types. The present study aimed to develop input values for a standard model for lowrise residential buildings; thus, the list of variables prescribed for mid-rise apartments (among the prototype's 16 building types) was examined. While EN ISO 50216 stipulates calculation methods to evaluate energy performance in residential and nonresidential buildings, it is not a 

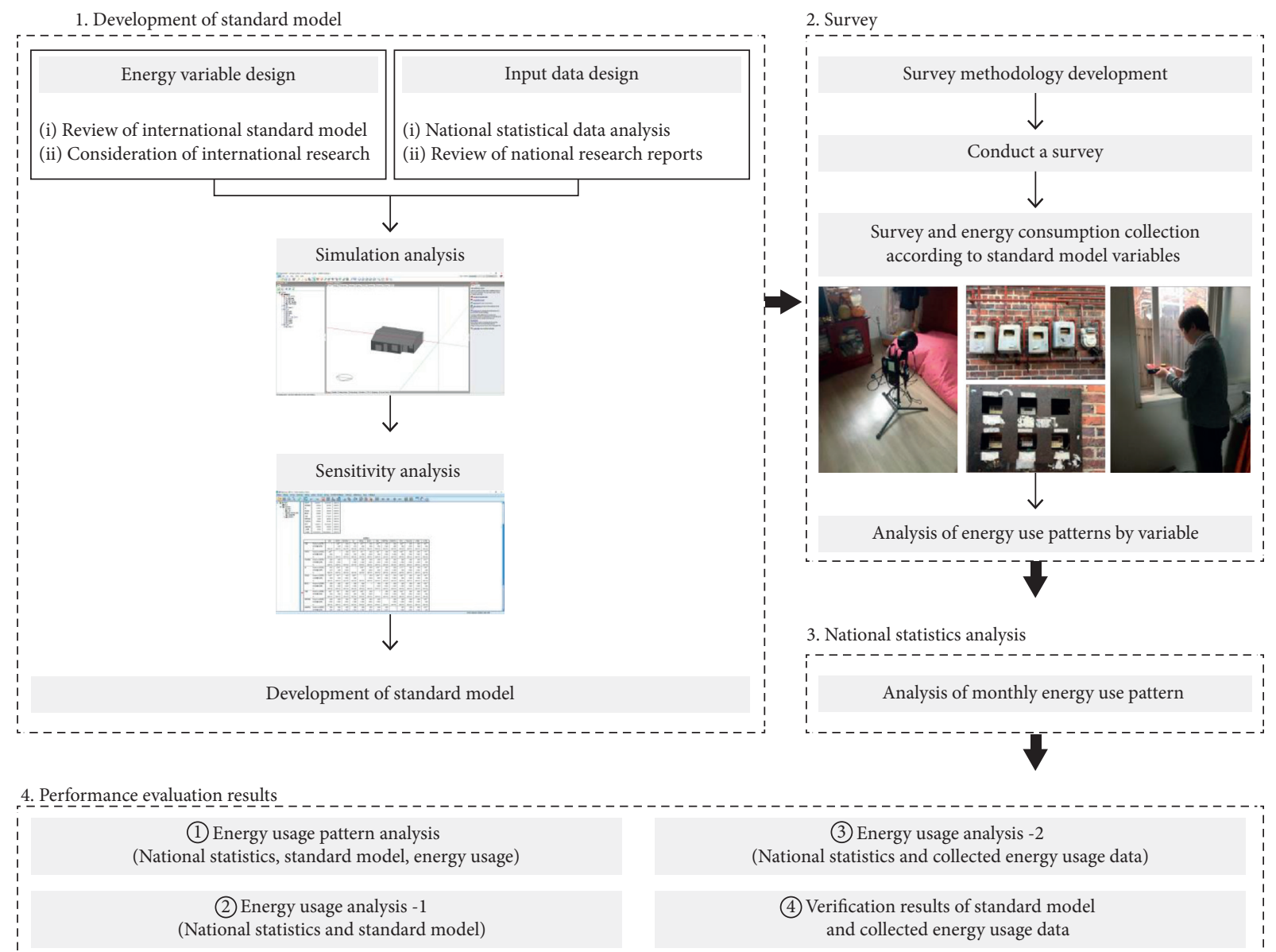

FIGURE 1: Schematic representation of the methodology used in this study.

standard model. Nonetheless, it provides variables and calculation formula for evaluating energy performance in buildings [34-37]. In particular, it is possible to calculate the heating and cooling loads using the time and monthly calculation method. Table 1 shows the variables associated with building energy performance.

\section{Methods}

2.1. Energy Variables Design. For developing a standard model in the present study, the energy variables were selected from those described in Korean standards, literature, and statistical data based on international standards and dynamic analysis simulation input variables, as shown in Table 2. The input data of each factor were selected and then validated through a sensitivity analysis. The variables used in our study belonged to three main categories: architecture, passive, and usage. "Architecture variables" refer to form and architectural elements; "passive variables" refer to building structures and heating, ventilation, and air-conditioning (HVAC) elements; and "usage variables" refer to residents' usage behavior (schedule). This is because the energy usage of a residential building is mainly related to its architectural elements, environmental factors (i.e., passive factors), and residents' usage patterns [38-44]. However, the HVAC elements are defined as fixed variables in Subsection 2.2.2.

The input data for the energy variables of our standard model were defined based on the statistical data of national institutions. However, the technical parts and occupant behavior (schedule), which are difficult to derive from the statistical data, were selected based on the relevant standards, research findings, and by measuring the energy use of 70 households in low-rise residential buildings of Korea (Figure 2).

2.1.1. Architecture Variable Design. The Korean Building Act has classified low-rise residential areas to include detached, multifamily, and row houses with four or fewer stories. An architecture variable is derived through the theoretical consideration of variables that can affect energy performance, such as plane and elevation type. In this study, the derived variables were investigated in terms of total floor area, inner and outer wall area ratio, number of toilets, number of resident spaces (rooms), window area ratio, number of balconies, and short- and long-side ratio in the floor plan. The factors of each variable were determined by analyzing the national statistical data of the Republic of Korea, and the details for each are explained below. 
TABLE 1: Study of international building energy performance variables (ASHRAE, 2016).

\begin{tabular}{|c|c|c|}
\hline Main Ca. & Category & Subclass \\
\hline Form & \multicolumn{2}{|c|}{$\begin{array}{l}\text { Total floor area, building shape, aspect ratio, number of floors, window fraction, window-to-wall ratio, } \\
\text { window locations, shading geometry, building orientation, thermal zoning, floor-to-floor height (ft), floor- } \\
\text { to-ceiling height (ft), glazing sill height }(\mathrm{ft})\end{array}$} \\
\hline \multirow{9}{*}{ Architecture } & Exterior walls & Construction, $U$-value, $R$-value \\
\hline & Roof & Construction, $U$-value, $R$-value \\
\hline & Window & Dimensions, glass (type and frame), U-value, SHGC, \\
\hline & & visible transmittance, operable area \\
\hline & Skylight & Glass (type and frame), U-value, SHGC, visible transmittance \\
\hline & Foundation & Foundation type, construction, F-value, dimensions \\
\hline & Interior partitions & Construction, dimensions \\
\hline & Internal mass & - \\
\hline & Air barrier system & Infiltration $(\mathrm{ACH})$ \\
\hline \multirow{6}{*}{ HVAC } & System type & Heating type, cooling type, distribution and terminal units \\
\hline & HVAC sizing & Air conditioning, heating \\
\hline & HVAC efficiency & Air conditioning, heating \\
\hline & HVAC control & $\begin{array}{l}\text { Thermostat setpoint, thermostat setback, supply air temperature, } \\
\text { economizers, ventilation, demand control ventilation, energy recovery }\end{array}$ \\
\hline & Supply fan & Fan schedules, supply fan total efficiency (\%), supply fan pressure drop \\
\hline & SWH & $\begin{array}{l}\text { SWH type, fuel type, thermal efficiency (\%), tank volume (gal), water temperature } \\
\text { set point, water consumption }\end{array}$ \\
\hline \multirow{3}{*}{ Internal loads and schedules } & Lighting & $\begin{array}{c}\text { Average power density }\left(\mathrm{W} / \mathrm{ft}^{2}\right) \text {, schedule, daylighting } \\
\text { controls, occupancy sensors }\end{array}$ \\
\hline & Plug load & Average power density $\left(\mathrm{W} / \mathrm{ft}^{2}\right)$, schedule \\
\hline & Occupancy & Average occupancy, schedule \\
\hline
\end{tabular}

ASHRAE : American Society of Heating, Refrigerating and Air-Conditioning Engineers; SHGC: solar heat gain coefficient; ACH: air changes per hour; HVAC: heating, ventilation, and air-conditioning; SWH: service water heating.

TABLE 2: List of energy variables used in this study.

\begin{tabular}{|c|c|c|c|c|}
\hline \multicolumn{2}{|l|}{ Main Category } & \multicolumn{2}{|c|}{ Category } & Subclass \\
\hline \multirow{10}{*}{\multicolumn{2}{|c|}{ Architecture variables }} & \multicolumn{2}{|c|}{ Building type } & - \\
\hline & & \multicolumn{2}{|c|}{ Total floor area } & - \\
\hline & & \multicolumn{2}{|c|}{ Building shape (plan form) } & - \\
\hline & & \multicolumn{2}{|c|}{ Window-to-wall ratio } & - \\
\hline & & \multicolumn{2}{|c|}{ Location } & Setting of insulation boundary condition \\
\hline & & \multicolumn{2}{|c|}{ Number of rooms } & Thermal zoning \\
\hline & & \multicolumn{2}{|c|}{ Number of bathrooms } & Thermal zoning \\
\hline & & \multicolumn{2}{|c|}{ Balcony form } & Thermal zoning \\
\hline & & \multicolumn{2}{|c|}{ Building orientation } & - \\
\hline & & \multicolumn{2}{|c|}{ Climate zone } & - \\
\hline \multirow{9}{*}{ Passive variables } & \multirow{4}{*}{ Building structures } & \multirow{4}{*}{ Construction year } & Window & U-value, SHGC \\
\hline & & & Exterior walls & $U$-value \\
\hline & & & Roof & $U$-value \\
\hline & & & Floors & $U$-value \\
\hline & \multirow{5}{*}{ HVAC } & Air barri & jstem & Infiltration $(\mathrm{ACH})$ \\
\hline & & Hea & & Heating type, heating efficiency \\
\hline & & $\mathrm{Coc}$ & & Cooling type, cooling efficiency \\
\hline & & Ligh & & Average power density \\
\hline & & Equipm & load & Average power density \\
\hline \multirow{3}{*}{ Usage variables } & & \multicolumn{2}{|c|}{ Occupancy } & Average people, schedule \\
\hline & & \multicolumn{2}{|c|}{ HVAC } & Schedule \\
\hline & & \multicolumn{2}{|c|}{ Lighting } & Schedule \\
\hline
\end{tabular}

HVAC: ventilation, and air-conditioning; SHGC: solar heat gain coefficient; ACH: air changes per hour. 


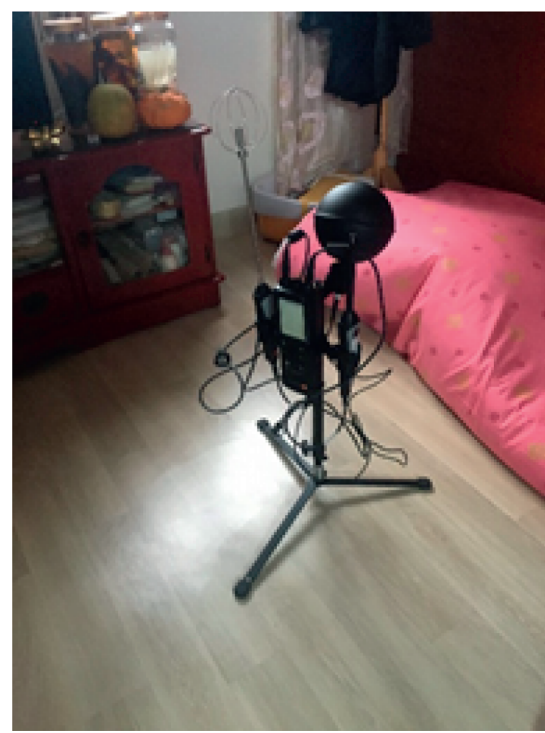

(a)

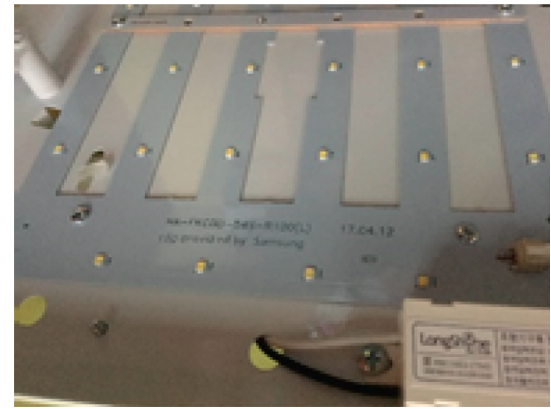

(d)

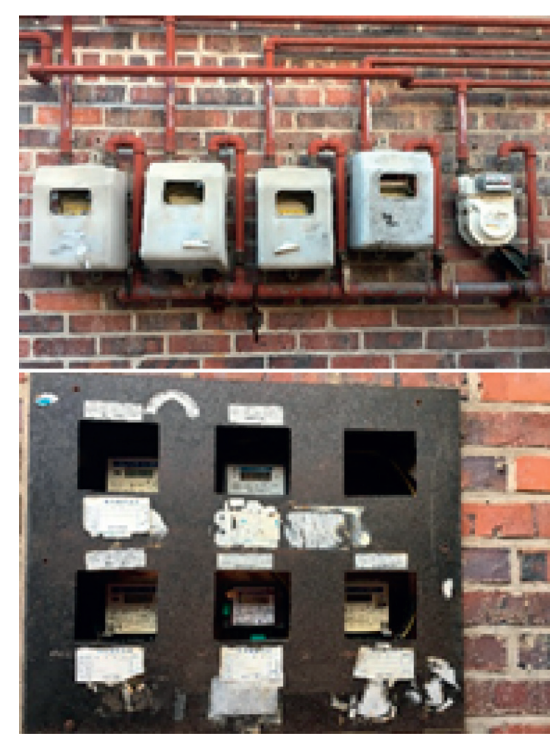

(b)

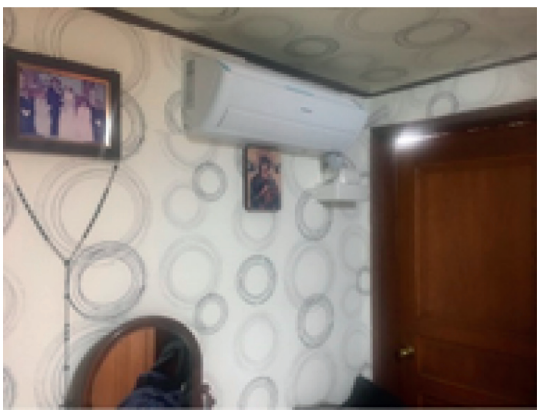

(e)

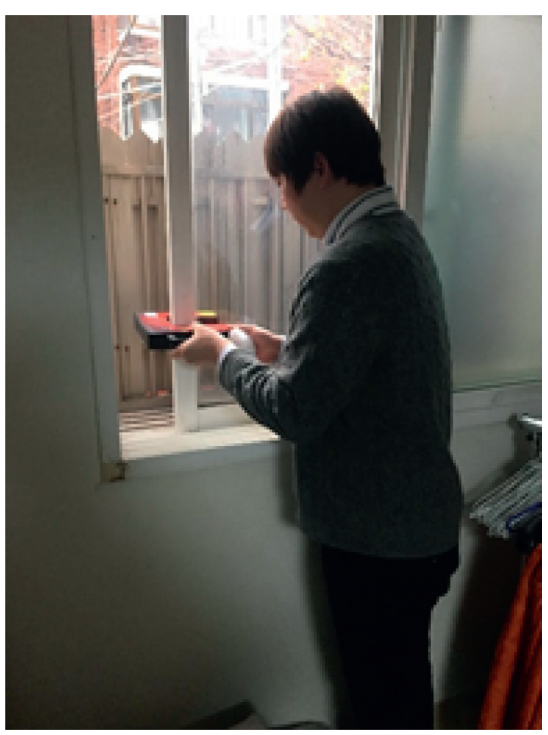

(c)

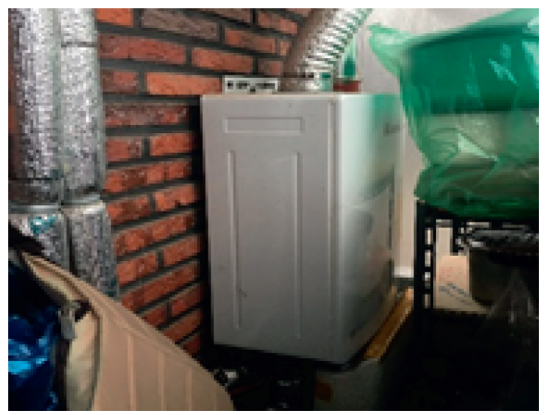

(f)

FIGURE 2: Field measurements in 70 low-rise residential buildings of Korea. (a) Indoor temperature. (b) Usage of electric, gas. (c) Window information. (d) Lighting. (e) Air conditioning. (f) Boiler heating.

The value of the variable total floor area was selected based on the national statistical data of the Republic of Korea [45], and its factors were selected by deriving the most frequent value within the total floor area by using the Architectural Administration Information System (AIS) data reported in the column titled Seumter [46]. Table 3 presents the number of households in Korea according to the housing type and floor area range. In order to select the most representative floor area range, over $10 \%$ of buildings were selected for each residential type. As Table 4 shows, obtaining the minimum number of buildings within a floor area range type resulted in the standard floor area values of $36,49,66,99$, and $109 \mathrm{~m}^{2}$ for detached houses; 39, 54, and $82 \mathrm{~m}^{2}$ for apartment units in private houses (or multifamily houses); and $39,59,66$, and $84 \mathrm{~m}^{2}$ for row houses. However, the range of 60 to $85 \mathrm{~m}^{2}$ for row houses was established by using two standard floor areas with similar distribution ratio.

A building's plane shape is a major factor that alters the outer wall area, which, in turn, can affect the heating and cooling loads. Plane types are investigated via physical and typological classification $[47,48]$. The physical space classification method is used to classify plane types according to room composition, i.e., the linkage of living room (L), dining room (D), and kitchen $(\mathrm{K})$, and plane shape, whereas the typological classification method is used to classify plane types according to the plane's shape or elevation. Owing to the traditional characteristics of Korean housing (L-D-K separation form) and the influence of industrialization (LDK combination type), the LDK linkage changes a building's floor plan and moving patterns. This, in turn, can be referred to as "usage separately" or "usage without distinction" differences according to the rooms' usage characteristics. Therefore, possible physical space classifications include L-DK (independent L), L-D-K (independent $L, D$, and $\mathrm{K}$ ), another room-linked LDK, and LD-K (independent $\mathrm{K}$ ). Typological classifications are made based on the floor plan's short- and long-side ratio. The horizontal-vertical ratio is classified as vertical rectangular if the ratio is less than $1: 2$, horizontal rectangular if it is below $2: 1$, and square if it is exactly $1: 1.12$. Figure 3 and Table 5 present these variables.

Heating type in Korea's residential areas is based on floor heating according to the traditional method; therefore, the floor for heating space is determined based on residential or nonresidential space. Therefore, the standard model was derived by selecting the number of rooms (heated spaces) 
TABLe 3: Derivation of floor area range through statistical analysis (KOSIS, Korea).

\begin{tabular}{|c|c|c|c|c|c|c|}
\hline \multirow{2}{*}{ Range of area } & \multicolumn{2}{|c|}{ Detached house } & \multicolumn{2}{|c|}{ Multifamily house } & \multicolumn{2}{|c|}{ Row house } \\
\hline & Count & Frequency rate & Count & Frequency rate & Count & Frequency rate \\
\hline$\sim 40 \mathrm{~m}^{2}$ & 430996 & $11 \%$ & 709533 & $34 \%$ & 49489 & $10 \%$ \\
\hline $40-60 \mathrm{~m}^{2}$ & 650359 & $16 \%$ & 853852 & $41 \%$ & 202215 & $40 \%$ \\
\hline $60-85 \mathrm{~m}^{2}$ & 871426 & $22 \%$ & 481184 & $23 \%$ & 197865 & $39 \%$ \\
\hline $85-100 \mathrm{~m}^{2}$ & 574651 & $15 \%$ & 13984 & $1 \%$ & 14546 & $3 \%$ \\
\hline $100-130 \mathrm{~m}^{2}$ & 387860 & $10 \%$ & 10133 & $0 \%$ & 15930 & $3 \%$ \\
\hline $130-165 \mathrm{~m}^{2}$ & 341501 & $9 \%$ & 3032 & $0 \%$ & 13125 & $3 \%$ \\
\hline $165-230 \mathrm{~m}^{2}$ & 319867 & $8 \%$ & 1187 & $0 \%$ & 7687 & $2 \%$ \\
\hline $230 \mathrm{~m}^{2} \sim$ & 386412 & $9 \%$ & 0 & $0 \%$ & 1657 & $0 \%$ \\
\hline
\end{tabular}

KOSIS : Korean Statistical Information Service.

TABLE 4: Derivation of standard areas within the floor area range (Ministry of Land, Infrastructure and Transport, Korea).

\begin{tabular}{lcccccc}
\hline \multirow{2}{*}{ Range of area } & \multicolumn{2}{c}{ Detached house } & \multicolumn{2}{c}{ Multifamily house } & \multicolumn{2}{c}{ Row house } \\
& Standard area & Frequency rate & Standard area & Frequency rate & Standard area & Frequency rate \\
\hline$\sim 40 \mathrm{~m}^{2}$ & $36 \mathrm{~m}^{2}$ & $9.1 \%$ & $39 \mathrm{~m}^{2}$ & $9.0 \%$ & $39 \mathrm{~m}^{2}$ & $9.3 \%$ \\
$40-60 \mathrm{~m}^{2}$ & $49 \mathrm{~m}^{2}$ & $8.3 \%$ & $54 \mathrm{~m}^{2}$ & $8.5 \%$ & $59 \mathrm{~m}^{2}$ & $8.5 \%$ \\
$60-85 \mathrm{~m}^{2}$ & $66 \mathrm{~m}^{2}$ & $6.1 \%$ & $82 \mathrm{~m}^{2}$ & $6.1 \%$ & $-3.3 \%$ & - \\
$85-100 \mathrm{~m}^{2}$ & $99 \mathrm{~m}^{2}$ & $19.1 \%$ & - & - & - & - \\
$100-130 \mathrm{~m}^{2}$ & $109 \mathrm{~m}^{2}$ & $4.1 \%$ & - & - & - \\
\hline
\end{tabular}
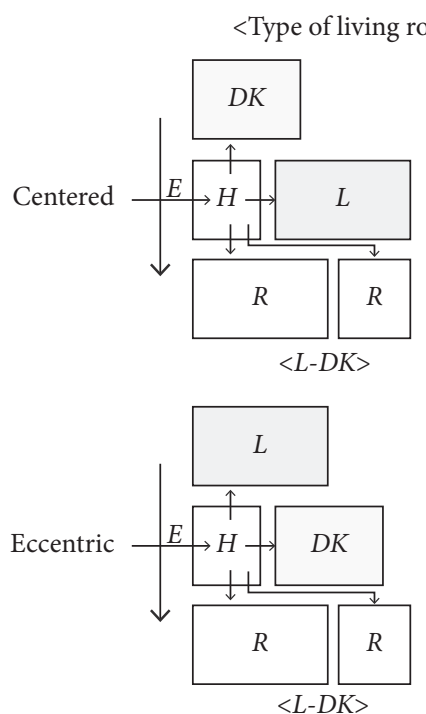
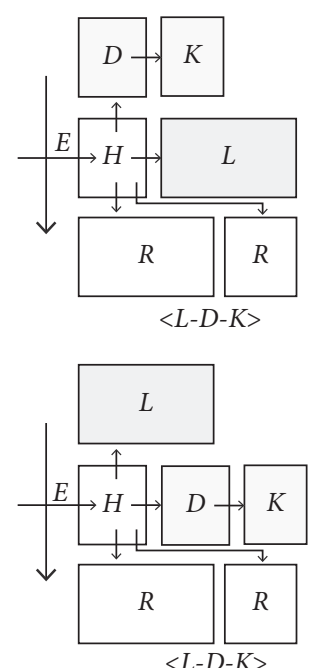

$<$ Type of other thread connection>
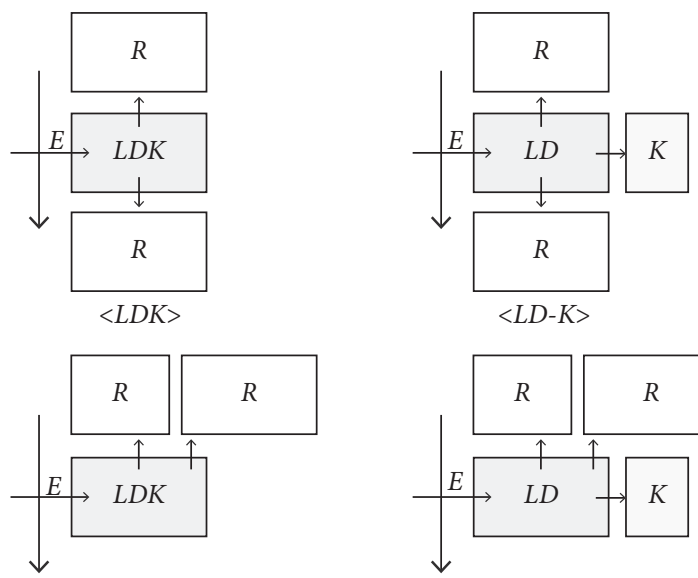

$<L D K>$

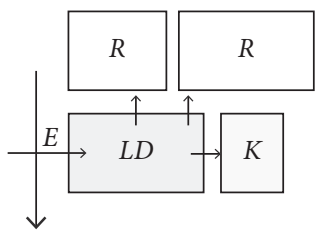

$<L D-K>$

Figure 3: Classification of physical space.

TABle 5: Classification of typology.

\begin{tabular}{lcc}
\hline Type & Copper wire type & Classification of space \\
\hline \multirow{2}{*}{ Rectangle } & Horizontal & $1: 2$ \\
& Vertical & $2: 1$ \\
Square & - & $1.12: 1$ \\
\hline
\end{tabular}

and toilets and balconies (unheated spaces) as variables in order to classify heating and nonheating spaces. The number of rooms was calculated by averaging the number of rooms within each area, as Table 6 shows, referring to the data from the Korean Statistical Information Service (KOSIS) [49]. However, the number of rooms presented by KOSIS is based on an independent space with four wall sides, excluding toilets. Therefore, for the standard model developed in this study, the number of toilets was arbitrarily selected according to the total floor area and number of rooms.

Heat loss often occurs through or around fittings (i.e., windows and doors) in buildings, compared to other structures (external walls, roofs, etc.). Thus, fittings are a major cause of building energy loss. In the winter season, heat transmission leads to heat loss, which, in turn, results in 
TABle 6: Derivation of standard area within area range (Ministry of Land, Infrastructure, and Transport, Korea).

\begin{tabular}{|c|c|c|c|c|c|c|c|c|}
\hline \multicolumn{3}{|c|}{ Detached house } & \multicolumn{3}{|c|}{ Multifamily house } & \multicolumn{3}{|c|}{ Row house } \\
\hline $\begin{array}{l}\text { Standard } \\
\text { area }\end{array}$ & $\begin{array}{l}\text { Number of } \\
\text { rooms }(N)\end{array}$ & $\begin{array}{c}\text { Number of } \\
\text { bathrooms }(N)\end{array}$ & $\begin{array}{c}\text { Standard } \\
\text { area }\end{array}$ & $\begin{array}{l}\text { Number of } \\
\text { rooms }(N)\end{array}$ & $\begin{array}{c}\text { Number of } \\
\text { bathrooms }(N)\end{array}$ & $\begin{array}{c}\text { Standard } \\
\text { area }\end{array}$ & $\begin{array}{c}\text { Number of } \\
\text { room }(N)\end{array}$ & $\begin{array}{c}\text { Number of } \\
\text { bathrooms }(N)\end{array}$ \\
\hline $36 \mathrm{~m}^{2}$ & $3-4$ & 1 & $39 \mathrm{~m}^{2}$ & $2-3$ & 1 & $39 \mathrm{~m}^{2}$ & $2-3$ & 1 \\
\hline $49 \mathrm{~m}^{2}$ & $4-5$ & $1-2$ & $54 \mathrm{~m}^{2}$ & $4-5$ & $1-2$ & $59 \mathrm{~m}^{2}$ & $3-4$ & $1-2$ \\
\hline $66 \mathrm{~m}^{2}$ & $5-6$ & $1-2$ & $82 \mathrm{~m}^{2}$ & $4-5$ & $1-2$ & $\begin{array}{l}66 \mathrm{~m}^{2} \\
84 \mathrm{~m}^{2}\end{array}$ & $\begin{array}{l}4-5 \\
4-5\end{array}$ & $\begin{array}{l}1-2 \\
1-2\end{array}$ \\
\hline $99 \mathrm{~m}^{2}$ & $5-6$ & $1-2$ & - & - & & - & - & \\
\hline $109 \mathrm{~m}^{2}$ & $6-7$ & $2-3$ & - & - & & - & - & \\
\hline
\end{tabular}

the heating load. Meanwhile, in the summer season, the generation of excessive solar radiation is the main cause of the cooling load. The energy consumption required to heat and cool a particular building varies highly depending on the total area of fittings. Therefore, the fitting area ratio (window area ratio) was derived as a main variable in this study. The fitting area ratios for residential buildings were set at $15 \%$, $20 \%$, and $25 \%$ after consulting the existing literature and onsite surveys [50, 51].

The Republic of Korea regulates balconies in a unique way; i.e., balconies are classified as service areas and are not included in the total floor area. A common trend in Korea has been to create wider residential areas by tearing down the walls of balconies and expanding them to be used as rooms. In these cases, balconies are included as heating spaces; however, they are excluded when calculating the floor area. Given that there were no relevant regulations and that houses without balconies existed before 1970, the balcony input values of the standard model variable were classified as none, expandable, and nonexpandable. In the standard model simulation, balconies were designed with $1.5-\mathrm{m}$ and $2-\mathrm{m}$ sides at the end of the outer wall in accordance with Korean building regulations.

The setting of the insulation boundary conditions is considered one of the major energy factors for multifamily and row housings, but not for single-family housings. This defines the spaces directly and indirectly in contact with the outside air and is thus believed to have a direct impact on the heating and cooling loads of various housings. Thus, a total of six module variables were established for side-layer housings (base floor, standard floor, and highest floor) and middle-layer housings (ground floor, standard floor, and highest floor), as shown in Figure 4.

2.1.2. Passive Variable Design. The passive variable is an environmental variable that can derive the heat transmission and infiltration rates according to a building's building orientation and completion year. The input values for each variable were set in accordance with the year of revision of the Republic of Korea Building Code.

A building's year of completion is a major indicator of the heat transmission rate of its structures, as indicated in the Building Energy Conservation Design Standards Manual (No. 2010-1031) published by the Ministry of Land, Infrastructure, and Transport of the Republic of Korea [52]. Considering that $75 \%$ of low-rise residential buildings in

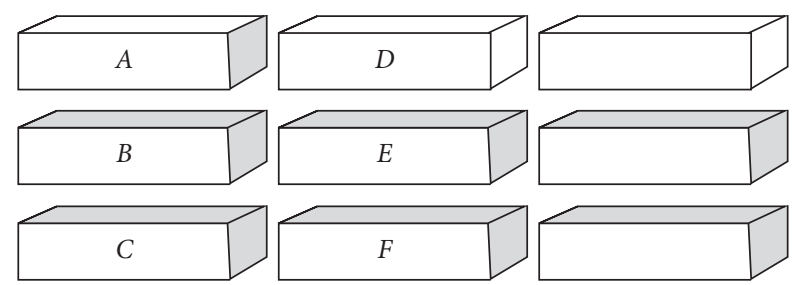

FIGURE 4: Setting of insulation boundary conditions.

Korea were completed prior to 2001, the standard completion years for buildings were classified based on the year when the U-value standard for each part of a building changed significantly or when a distinction occurred depending on the building type, as shown in Figure 5. Thus, the classification categories were set as prior to 1980, prior to 1987, and prior to 2001, as Table 7 shows. The insulation type was set as an internal insulation structure, and the simulation was performed by changing the thickness of the insulation material based on the heat transmission rate according to the year of completion.

A buildings' building orientation is another main factor influencing its heating and cooling loads, as it is a major variable in the acquisition of solar radiation. In particular, south-facing buildings receive ample solar radiation in winters, thus requiring less heating load. In contrast, northfacing buildings are expected to require the highest heating load; however, they were excluded from this study because residential facilities are rarely oriented toward the north. Although the west is more affected by solar radiation than the east, the east/west direction was assumed to be the same when a variable's input value was selected. Therefore, the input values of the directions of a building were categorized as South- $0^{\circ}$, East (West) $-45^{\circ}$, and Southeast (Southwest)- $90^{\circ}$.

2.1.3. Usage Variable Design. Usage variable is a variable related to the usage pattern of a building; for example, the amount of heat generated by an occupant's schedule and the number of occupants in a building are designated as usage variables. An occupant's schedule is controlled in three stages, based on the type of commuting in the Republic of Korea. The Korean Labor Law defines normal working hours as 8 hours per day for adult workers over 18 years of age, and according to the statistics on the "types of working hours and number of working hours per week," 59\% workers work 40-44 hours per week [53]. According to the "analysis of the 


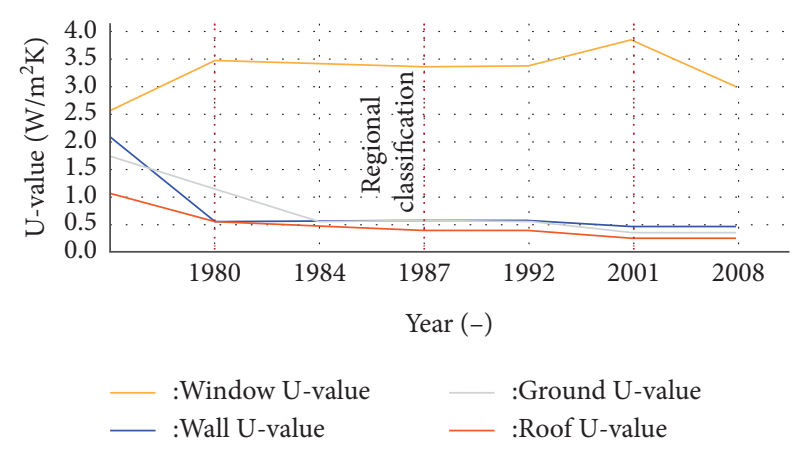

FIgURE 5: Changes in U-value by year.

TABLe 7: U-values in different years $\left(\mathrm{W} / \mathrm{m}^{2} \mathrm{k}\right)$.

\begin{tabular}{ccccc}
\hline Year & Wall & Roof & Ground & Window \\
\hline 1980 & 1.047 & 1.047 & 1.047 & 3.489 \\
1987 & 0.582 & 0.582 & 0.582 & 3.489 \\
2001 & 0.582 & 0.407 & 0.582 & 3.373 \\
\hline
\end{tabular}

statistical status of working hours" by the Statistics Research Institute, $64 \%$ workers are daytime workers [54]. Therefore, an occupant's schedule is controlled based on an 8-hour workday of a typical daytime worker, with a general workday in Korea including working hours from 9:00 to 18:00. Therefore, a user's commuting time and sleeping time were classified into three categories as $00: 00$ to $08: 00,08: 00$ to $18: 00$, and $18: 00$ to $24: 00$, as shown in Table 8 , and the actual rates were set to $0 \%, 25 \%, 50 \%, 75 \%$, and $100 \%$ based on the commuting time of $08: 00$ to $18: 00[55,56]$. This represents the rate of frequency of an occupant who lives at home during the rush hour, with $0 \%$ rate implying no occupant to stay at home and $100 \%$ implying no people to go to work. In addition, the input values of the number of occupants in a room were divided into three categories (2 people, 3 people, and 4 people). The amount of heat generated by the human body according to the number of occupants in a room was calculated using the following equation:

$$
\text { density }=\frac{\text { number of people }}{\text { building area }\left(\mathrm{m}^{2}\right)} \text {. }
$$

\subsection{Variable Sensitivity Analysis}

2.2.1. Sensitivity Analysis of Energy Variables. In this study, the energy variables for sensitivity analysis were based on the variables derived in Subsection 2.1. Each variable's level was set according to Table 9. A total of 14 factors were selected as independent variables in order to analyze the sensitivity of the factors and energy requirements [57-61]. The simulation was conducted after reducing the physical space to four levels in the most commonly used forms. The numbers of toilets and rooms vary depending on the floor area; moreover, each floor area had two levels, $A$ and $B$. The $U$ value and infiltration of each outer wall were set according to each building's year of completion.
2.2.2. Simulation Setting. This study performed a simulation analysis to determine energy consumption by outputting energy-influencing factors through the sum of energy consumption and sensitivity analysis of the variables. This enabled the development of factors for the standard model. This study utilized DesignBuilder 4.7, a graphical user interface based on EnergyPlus' engine. Owing to the large amount of data on the variables, modeling was conducted in DesignBuilder, and the simulation was performed employing EnergyPlus macros using the Python eppy tool. Table 9 presents the standard model's variable input values for simulation, while Table 10 presents additional factors [62-64]. Considering that Korean dwellings use floor heating, HVAC was set as heat floor, boiler hot water (HW), and natural ventilation, which are the default components of DesignBuilder. The heat source efficiency of heating and cooling equipment was determined based on the Ministry of Trade, Industry, and Energy's "Regulations for Managing the Energy Efficiency of Equipment (2011)." Household gas boilers were selected as the heating equipment, and the efficiency (coefficient of performance) was set to $81 \%$, the minimum heating consumption efficiency standard defined since 2003. For cooling equipment, the simulation was performed by setting the minimum consumption efficiency standard to 2.88 for integrated air conditioners [65]. Natural ventilation was set to 0.5 air changes per hour $(\mathrm{ac} / \mathrm{h}$; residential ventilation) in accordance with Korea's "Building Equipment Standard Rules," and the infiltration rate was set to $1.25 \mathrm{ac} / \mathrm{h}$, in accordance with "A Study on the Development of Energy Simulation Tool for Green Remodeling Contractor" by the Korea Land and Housing Corporation [66]. In terms of climate data, the simulation used the data from Seoul, the capital of South Korea. The temperature values were set to $20^{\circ} \mathrm{C}$ for heating and $26^{\circ} \mathrm{C}$ for air conditioning, according to the Energy Saving Design Criteria of Buildings published by the Ministry of Land, Infrastructure, and Transport. The lighting density was set to $10 \mathrm{~W} / \mathrm{m}^{2}$ based on the Construction Standards for Energy-saving Ecofriendly Houses (Ministry of Land, Infrastructure, and Transport Notice No. 2018-533), which stipulate that the sum of the capacities of lighting fixtures installed in the living room of a household divided by the exclusive area should be $10 \mathrm{~W} / \mathrm{m}^{2}$ or less. The amount of heat generated by equipment was set to $2.17 \mathrm{~W} / \mathrm{m}^{2}$ based on the Korean building energy efficiency certification system operating regulations [67].

2.2.3. Results of Sensitivity Analysis. Table 11 displays the results of a correlation analysis between the sum of energy consumption and the variables used in this study. The correlation between variables was found to be significant under the 0.01 significance level, except for the classification of physical space and inner and outer wall area ratio. The effects of variables on energy requirements were found to be in the following order: $x_{2} x_{1}, x_{9}, x_{6}, x_{7}$, $x_{11}, x_{14}, x_{3}, x_{8}, x_{10}, x_{12}, x_{13}, x_{4}, x_{3}$. Therefore, the selected variables were area, short- and long-side ratio in the floor plan, number of rooms, balcony type, insulation 
TABLE 8: Setting of schedules in a room.

\begin{tabular}{lccc}
\hline Variable level & & Rate of occupancy \\
$08: 00-18: 00$ & $18: 00-24: 00$ \\
\hline $0 \%$ & $24: 00-08: 00$ & $0 \%$ & $100 \%$ \\
$25 \%$ & $100 \%$ & $25 \%$ & $100 \%$ \\
$50 \%$ & $100 \%$ & $50 \%$ & $100 \%$ \\
$75 \%$ & $100 \%$ & $75 \%$ & $100 \%$ \\
$100 \%$ & $100 \%$ & $100 \%$ & $100 \%$ \\
\hline
\end{tabular}

TABle 9: Definition by variable.

\begin{tabular}{|c|c|c|c|}
\hline Variables & Units & Character & Variables input data \\
\hline \multirow[t]{2}{*}{ Type of building } & - & & Detached house, multifamily house, row house \\
\hline & $\mathrm{m}^{2}$ & Detached house & $39,49,66,99,109$ \\
\hline \multirow[t]{2}{*}{ Area } & $\mathrm{m}^{2}$ & $\begin{array}{l}\text { Multifamily } \\
\text { house }\end{array}$ & $39,54,82$ \\
\hline & $\mathrm{m}^{2}$ & Small house & $39,59,66,84$ \\
\hline $\begin{array}{l}\text { Short- and long-side ratio in } \\
\text { the floor plan }\end{array}$ & - & & Vertical rectangular $(1: 2)$, horizontal rectangular $(2: 1)$, square $(1.12: 1)$ \\
\hline Classification of physical space & - & & $\begin{array}{c}\text { Standalone-centered (L-DK), connection-centered (LDK), standalone-eccentric } \\
\text { (L-DK), connection-eccentric (LDK) }\end{array}$ \\
\hline Inner and outer wall area ratio & - & & $1: 1.5,1: 2,1: 2.5$ \\
\hline Number of rooms & - & & $A, B$ \\
\hline Number of toilets & - & & $A, B$ \\
\hline Balcony type & - & & None, expandable, nonexpandable \\
\hline Insulation boundary condition & - & & $\begin{array}{c}A \text { (side layer-highest floor), } B \text { (side layer-standard floor), } C \text { (side layer-base } \\
\text { floor), } D \text { (middle layer-highest floor), } E \text { (middle layer-standard floor), } F \\
\text { (middle layer-base floor) }\end{array}$ \\
\hline Window area ratio & $\%$ & & $15 \%, 20 \%, 25 \%$ \\
\hline Year of completion & - & $\begin{array}{l}\text { U-value }(\mathrm{W} / \\
\left.\mathrm{m}^{2} \mathrm{k}\right)\end{array}$ & $\begin{array}{l}1980 \text { [wall }(1.047) \text {, roof }(1.047) \text {, ground }(1.047) \text {, window }(3.489) \text { ], } \\
1987 \text { [wall }(0.582) \text {, roof }(0.582) \text {, ground }(0.582) \text {, window }(3.489) \text {, } \\
2001 \text { [wall }(0.582) \text {, roof }(0.407) \text {, ground }(0.582) \text {, window }(3.373) \text { ] }\end{array}$ \\
\hline Building orientation & - & & South, east (west), southeast (southwest) \\
\hline Occupancy & Men & & $2,3,4$ \\
\hline Room schedule & $\%$ & & $0,25,50,75,100$ \\
\hline
\end{tabular}

TABLE 10: Setting of simulation.

\begin{tabular}{lc}
\hline Contents & Value \\
\hline HVAC & Heat floor, boiler HW, PTAC, natural ventilation \\
Cooling temperature & $26^{\circ} \mathrm{C}$ \\
Heating temperature & $20^{\circ} \mathrm{C}$ \\
Natural ventilation & $0.5 \mathrm{ac} / \mathrm{h}$ \\
Airtightness & $1.25 \mathrm{ac} / \mathrm{h}$ \\
Cooling coefficient of performance & $81 \%(\mathrm{gas})$ \\
Heating coefficient of performance & 2.88 \\
Lighting density & $10 \mathrm{~W} / \mathrm{m}^{2}$ \\
Office equipment & $2.17 \mathrm{~W} / \mathrm{m}^{2}$
\end{tabular}

HW: hot water; PTAC: packaged terminal air conditioner; ac/h: air changes per hour.

boundary condition, window area ratio, year of completion, region, number of people in each room, building orientation, and room schedule.

2.3. Survey Design. A questionnaire was designed to verify the variables and the proposed standard model's actual energy use. The survey was administered with ordinary people living in low-rise residential areas in Korea. In this survey, respondents' general information (age, gender, etc.) was collected to distinguish their characteristics. In addition, the survey collected general information regarding residential buildings to investigate the study's variables (housing type, floor area, short- and long-side ratio in the floor plan, number of rooms, number of toilets, balcony type, and window area ratio). The general information related to the 
TABLE 11: Results of sensitivity analysis.

\begin{tabular}{|c|c|c|c|c|}
\hline & Variable & Contents & Value & Selected variables \\
\hline$x 1$ & Type of building & $\begin{array}{l}\text { Pearson correlation coefficient } \\
\text { Significant probability (both) }\end{array}$ & $\begin{array}{c}-0.483^{* *} \\
0.000\end{array}$ & O \\
\hline$x 2$ & Area & $\begin{array}{l}\text { Pearson correlation coefficient } \\
\text { Significant probability (both) }\end{array}$ & $\begin{array}{c}0.775^{* *} \\
0.000\end{array}$ & 0 \\
\hline$x 3$ & Short- and long-side ratio in the floor plan & $\begin{array}{l}\text { Pearson correlation coefficient } \\
\text { Significant probability (both) }\end{array}$ & $\begin{array}{c}-0.072^{* *} \\
0.000\end{array}$ & 0 \\
\hline$x 4$ & Classification of physical space & $\begin{array}{l}\text { Pearson correlation coefficient } \\
\text { Significant probability (both) }\end{array}$ & $\begin{array}{l}0.001 \\
0.000\end{array}$ & $x$ \\
\hline$x 5$ & Inner and outer wall area ratio & $\begin{array}{l}\text { Pearson correlation coefficient } \\
\text { Significant probability (both) }\end{array}$ & $\begin{array}{l}0.001 \\
0.000\end{array}$ & $x$ \\
\hline$x 6$ & Number of rooms & $\begin{array}{l}\text { Pearson correlation coefficient } \\
\text { Significant probability (both) }\end{array}$ & $\begin{array}{c}0.339^{* *} \\
0.000\end{array}$ & 0 \\
\hline$x 7$ & Number of toilets & $\begin{array}{l}\text { Pearson correlation coefficient } \\
\text { Significant probability (both) }\end{array}$ & $\begin{array}{c}0.245^{* *} \\
0.000\end{array}$ & 0 \\
\hline$x 8$ & Balcony type & $\begin{array}{l}\text { Pearson correlation coefficient } \\
\text { Significant probability (both) }\end{array}$ & $\begin{array}{c}0.056^{* *} \\
0.000\end{array}$ & 0 \\
\hline$x 9$ & Insulation boundary condition & $\begin{array}{l}\text { Pearson correlation coefficient } \\
\text { Significant probability (both) }\end{array}$ & $\begin{array}{c}-0.432^{* *} \\
0.000\end{array}$ & \\
\hline$x 10$ & Window area ratio & $\begin{array}{l}\text { Pearson correlation coefficient } \\
\text { Significant probability (both) }\end{array}$ & $\begin{array}{c}0.035^{* *} \\
0.000\end{array}$ & 0 \\
\hline$x 11$ & Year of completion & $\begin{array}{l}\text { Pearson correlation coefficient } \\
\text { Significant probability (both) }\end{array}$ & $\begin{array}{c}-0.233^{* *} \\
0.000\end{array}$ & 0 \\
\hline$x 12$ & Building orientation & $\begin{array}{l}\text { Pearson correlation coefficient } \\
\text { Significant probability (both) }\end{array}$ & $\begin{array}{c}0.032^{* *} \\
0.000\end{array}$ & 0 \\
\hline$x 13$ & Occupancy (number of people in a room) & $\begin{array}{l}\text { Pearson correlation coefficient } \\
\text { Significant probability (both) }\end{array}$ & $\begin{array}{c}-0.005^{* *} \\
0.000\end{array}$ & 0 \\
\hline$x 14$ & Room schedule & $\begin{array}{l}\text { Pearson correlation coefficient } \\
\text { Significant probability (both) }\end{array}$ & $\begin{array}{c}0.139^{* *} \\
0.000\end{array}$ & 0 \\
\hline$x 15$ & Energy requirements & $\begin{array}{l}\text { Pearson correlation coefficient } \\
\text { Significant probability (both) }\end{array}$ & $\begin{array}{l}1 \\
-\end{array}$ & 0 \\
\hline
\end{tabular}

${ }^{* *}$ The correlation coefficient is significant at the 0.01 level (both sides).

TABLE 12: Variables for Survey design.

\begin{tabular}{|c|c|c|}
\hline Main & Category & Items of questionnaire \\
\hline \multirow{3}{*}{ Responder general } & Date of completion & - \\
\hline & Age & $20 \mathrm{~s} / 30 \mathrm{~s} / 40 \mathrm{~s} / 50 \mathrm{~s} / 60 \mathrm{~s} / 70 \mathrm{~s}$ \\
\hline & Sex & Male/female \\
\hline \multirow{10}{*}{ Architect general } & Type of building & Detached house/multifamily house/small house \\
\hline & & When "detached house" is selected: $36 / 49 / 66 / 99 / 109$ \\
\hline & Total floor area of the building & When "multifamily house" is selected: $39 / 54 / 82$ \\
\hline & & When "small house" is selected: $39 / 59 / 66 / 84$ \\
\hline & Short- and long-side ratio in the floor plan & Rectangle (horizontal)/rectangle (vertical)/square \\
\hline & Number of rooms & $1 / 2 / 3 / 4 / 5 / 6 / 7$ \\
\hline & Number of toilets & $1 / 2 / 3$ \\
\hline & Balcony type & None/expandable/nonexpandable \\
\hline & Insulation boundary condition & $\mathrm{A} / \mathrm{B} / \mathrm{C} / D / E / \mathrm{F}$ \\
\hline & Window area ratio & $15 \% / 20 \% / 25 \%$ \\
\hline \multirow{3}{*}{ Passive general } & Year of completion & $1980 / 1987 / 2001$ \\
\hline & Region & Central/Southern/Jeju \\
\hline & Building orientation & South/southeast/east \\
\hline \multirow{2}{*}{ Usage general } & Family members & $2 / 3 / 4$ \\
\hline & Room schedule & Person who lives in house during $08: 00-18: 00: 1 / 2 / 3 / 4$ \\
\hline
\end{tabular}

passive (completion year, region, and building orientation) and usage variables (number of family members and number of people occupying each room) was also gathered. Each item of respondents' general information was assessed and measured through individual responses (Table 12). The survey featured multiple-choice questions, but to verify the variables of the survey, only a single optimal response was possible to be chosen from the presented multiple-choices.

Owing to the difficulties in complete enumeration of low-rise dwellings, the surveys and usage information were 
collected through a sample survey. Subsequently, the proposed standard model was verified. However, this study does not focus on sample accuracy, but rather on estimating samples and verifying them through standard models. The confidence level was set at 90\% [68-70], and the survey design was based on population samples. Sample sizes were measured, and the survey was developed using the following formula:

$$
\text { sample size }=\frac{z^{2} \times p(1-p) / e^{2}}{1+z^{2} \times p(1-p) / e^{2} N} .
$$

where $N$ is the population size (the total number of people in the group to be analyzed); $e$ is the margin of error (percentage in decimal format); $Z$ is the $z$-score corresponding to the confidence level, $90 \%=1.65$; and $P$ is the observed percentage $(P=0.5$ was used to obtain the maximum sample error).

$N$ was selected as the number within the total floor area of low-rise dwellings adopted as the standard model, and the total number was set at 5409430 . $e$ indicates the level to which survey results can be expected to reflect the overall residential group's perspective, with the margin of error set at $10 \% . z$ represents the $z$-score, set to a $90 \%$ confidence level. Therefore, the sample size was 67 , which was ultimately set as 70 households by rounding up the number to the nearest tens.

The survey was conducted by reclassifying the number of samples according to the ratio of building type and total floor area of the standard model, a fixed variable, as shown in Table 13. This study was limited to the central region of Korea; therefore, 70 households were selected from low-rise residential buildings in Seoul, to conduct a survey on actual energy usage. The survey was administered with general public residents living in low-rise dwellings. The researchers actually visited the area for approximately 3 months from December 2018 to April 2019 to explain the relevant items, distribute the questionnaire, and collect a total of 70 responses. The relevant agencies provided support to complete the surveys. Table 14 presents the results of organizing the completed questionnaires by variable. The numbers of rooms and toilets were excluded from the calculation of the number of survey results because they were dependent variables according to the total floor area.

2.4. Collecting Energy Usage. The energy usage of questionnaire respondents was collected by obtaining the electrical and gas customer numbers granted to each respondent and looking them up online (see Figure 6 for this method of collection). Energy usage for this study was collected between January and December of 2018. Figures 7 and 8 present an analysis of the monthly distribution of energy usage in the buildings studied. According to the data collected, the amount of electricity used for cooling increased during summer (June to September), while the use of gas increased during winter (December to February). In terms of electricity usage, it was estimated that the use of household appliances and lighting equipment does not vary according to season under the base load (even if there is a slightly higher usage trend in the summer and winter seasons than during the interseason period because of the use of air conditioners in the summer and electric heating appliances in the winter). Therefore, the collected energy usage bills were determined to be reasonable for low-rise residential areas because they showed trends (patterns) that reflected the climate characteristics of Korea.

2.5. National Statistics Analysis. Statistics on energy usage in Korea's low-rise dwellings can be found in a report published by the Republic of Korea Energy Economics Institute, titled "Studies on Building Energy Policy through Analysis of Factors of Energy Consumption for Residential Buildings" [71]. The report's statistical data are based on 2520 samples. Energy use is classified by housing type, year of completion, and total floor area variables. While the report determined the mean, minimum, and maximum values of each sample, the raw data could not be determined. The National Statistics Analysis data are shown in Table 15, where the average annual energy consumption was determined to be $13027 \mathrm{kWh}$, while the standard deviation was $7143 \mathrm{kWh}$. Regarding energy consumption by housing type, the detached houses were found to use more energy than the other low-rise residential types, with a maximum deviation of $520 \mathrm{kWh}$. The year of completion variable indicates that the houses built between 1980 and 1989 use the least amount of energy. The heat transmission rate of building structures was theoretically estimated to be low because of the improvement of the energy consumption rate based on the year of completion. However, this finding can be attributed to evaluating energy consumption statistics based only on the year of completion without considering any other factors. Therefore, classifying and analyzing residents' energy consumption trends, number of households, or housing area according to the year of completion will make the resulting energy usage trends more accurate. In terms of statistical classification according to the total floor area of a house, the smaller the floor area, the lower the average energy usage.

\section{Performance Evaluation Results}

3.1. Energy Usage Pattern Analysis (National Statistics, Standard Model, Energy Usage). This study extracted variables for its standard model considering specific characteristics of the Republic of Korea and developed input values for all variables of Korea's low-rise residential buildings based on those characteristics. To verify the model and variables, the study also collected the energy usage patterns of 70 households through national standard models and sample surveys. Therefore, Subsection 3.1 presents an analysis of the proposed standard model, national statistics, and the consumption patterns of the obtained energy usage data. The analysis was performed based on dwelling type, floor area, and year of completion. Figures 9 and 10 show the analysis results, which are described below.

The analysis of the building type variables, proposed standard model, collected energy usage data, and national 
TABLE 13: Survey design sample according to building type and area.

\begin{tabular}{|c|c|c|c|c|c|c|}
\hline \multirow{2}{*}{ Range of area } & \multicolumn{2}{|c|}{ Detached house } & \multicolumn{2}{|c|}{ Multifamily house } & \multicolumn{2}{|c|}{ Row house } \\
\hline & Standard area & Specimen $(n)$ & Standard area & Specimen $(n)$ & Standard area & Specimen $(n)$ \\
\hline$\sim 40 \mathrm{~m}^{2}$ & $36 \mathrm{~m}^{2}$ & 6 & $39 \mathrm{~m}^{2}$ & 1 & $39 \mathrm{~m}^{2}$ & 9 \\
\hline $40-60 \mathrm{~m}^{2}$ & $49 \mathrm{~m}^{2}$ & 8 & $54 \mathrm{~m}^{2}$ & 3 & $59 \mathrm{~m}^{2}$ & 11 \\
\hline $60-85 \mathrm{~m}^{2}$ & $66 \mathrm{~m}^{2}$ & 11 & $82 \mathrm{~m}^{2}$ & 3 & $\begin{array}{l}66 \mathrm{~m}^{2} \\
84 \mathrm{~m}^{2}\end{array}$ & $\begin{array}{l}3 \\
3\end{array}$ \\
\hline $85-100 \mathrm{~m}^{2}$ & $99 \mathrm{~m}^{2}$ & 7 & - & - & - & - \\
\hline $100-130 \mathrm{~m}^{2}$ & $109 \mathrm{~m}^{2}$ & 5 & - & - & - & - \\
\hline
\end{tabular}

TABLE 14: Results of survey.

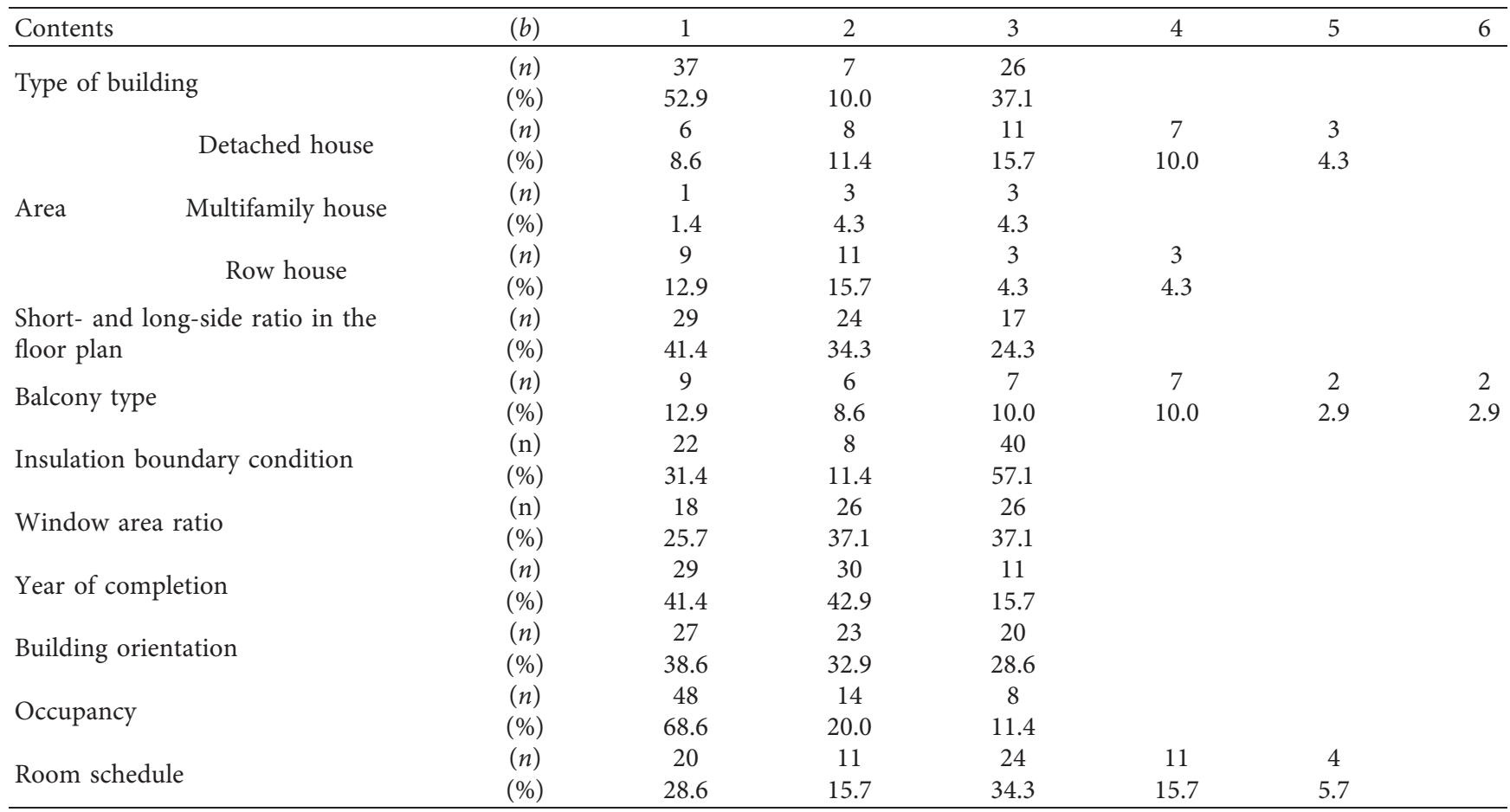

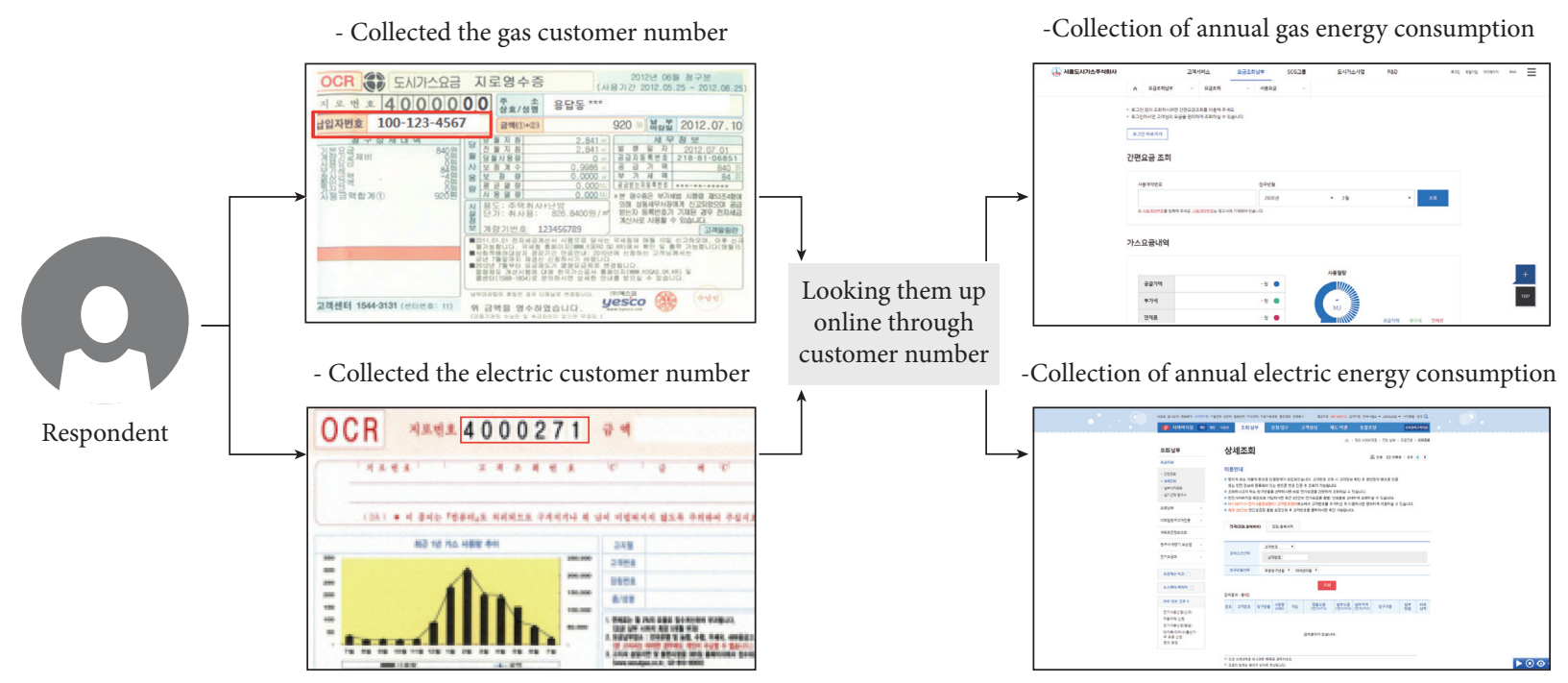

Figure 6: Method for collecting energy usage. 


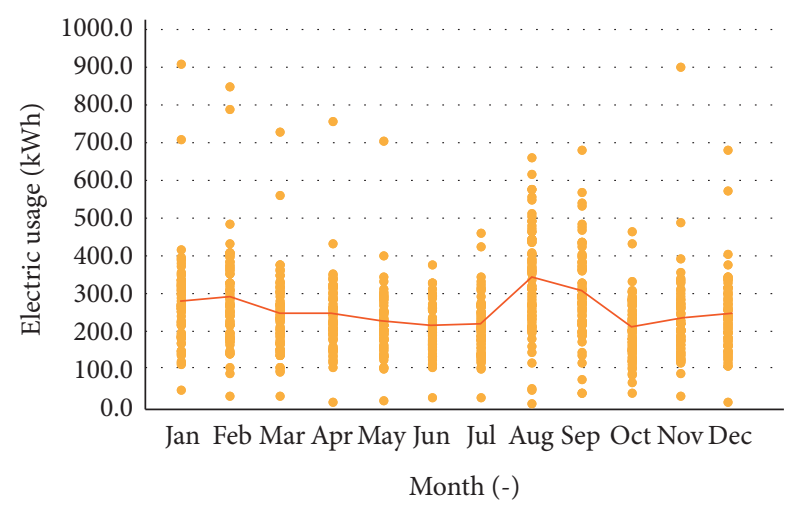

FIgUre 7: Monthly electric usage (data collected through utility bills).

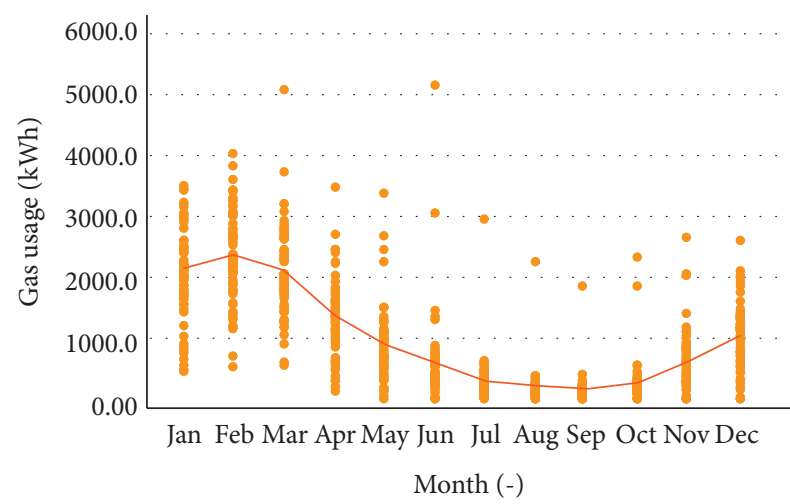

Figure 8: Monthly gas usage (data collected through utility bills).

statistics show the same pattern: energy usage is the highest in detached houses, then row houses, and finally multifamily houses. The amount of gas and electrical energy usage in detached houses was estimated to be higher than in multifamily and row houses because the heat loss is directly caused by volume ratio, given that the walls of detached houses are directly in contact with the outside air. Multifamily and row houses appear to have similar energy usage patterns because these building types are defined similarly by the Korean law (multifamily and row houses are classified according to regulations on total floor area and number of floors in a building).

An analysis of the total floor area variable of buildings revealed that the proposed standard model, collected energy usage data, and national statistics show the same pattern, that is, as the total floor area increases, energy use also increases. However, in the case of the study's usage data, the gas and electrical energy use increased as the total floor area increased, but the average energy use in each floor area did not increase steadily. This was because the data were collected from only 70 households; thus, owing to the small number of cases and the varying pattern of residents' energy consumption, the amount of energy usage was not proportional to the total floor area.

Based on the analysis of the variables studied, the heat transmission rates of building structures have been generally lower in recent years. Moreover, the gas use is expected to be lower in the winter season because of better infiltration performance. In the summer season, owing to good heat insulation, the greenhouse effect is expected to increase the use of air-conditioning (electricity). The results of the gas usage pattern analysis revealed a pattern of lower gas usage for both the standard model and collected usage data; however, in the case of the national statistics, the average energy usage by the year of completion showed similar values from 1980 to 2001, followed by a slight increase in 2001. This study found that the energy use trends change with the inclusion of certain factors, such as total floor area. This was especially true when the statistics data were derived from the national statistics through a sample survey rather than through a complete enumeration survey without considering other factors. Based on the analysis of electricity usage patterns, the standard model and national statistics showed the same pattern of increasing energy use; however, the collected energy usage data exhibited a pattern of decreasing energy use depending on the year of completion. The above results can be attributed to variations in residents' energy consumption patterns.

\subsection{Energy Usage Analysis (National Statistics and Collected} Energy Usage Data). The energy usage data collected in this study were verified by comparing them with the national energy usage statistics data. Table 16 and Figure 11 show the results, and the details are as follows.

In this study, the verification of energy usage by building type revealed that the minimum to maximum (min-max) ranges of the gas usage of detached, multifamily, and row houses were 1628-48 473, 1531-60 719, and 1901-105297 $\mathrm{kWh}$ according to national statistics and 2563-29636, 10371-14599, and 6194-19435 kWh according to the collected energy usage, respectively. The min-max electricity usage ranges for detached, multifamily, and row houses were 572-17 031, 538-21 333, and 668-36996 kWh according to the national statistics and 1764-4144, 2088-4544, and 1222-7346 kWh according to the collected energy usage, respectively. It was determined that all collected usage data fell within the scope of the national statistics. However, the average energy usage values exhibited a difference of 1646, 3130 , and $2366 \mathrm{kWh}$ for gas usage and 524, 281, and $78 \mathrm{kWh}$ for electricity usage, respectively.

The study also verified energy usage according to the years of completion of buildings. The min-max gas usage ranges for the years 1980, 1987, and 2001 were 1628-30 439, $1790-105297$, and $1901-101088 \mathrm{kWh}$ according to the national statistics and 6194-29636, 4866-23 253, and 2563-13507 kWh according to the collected energy usage, respectively. The min-max electricity usage ranges in 1980,1987, and 2001 were 572-10694, 628-36996, and $668-35517 \mathrm{kWh}$ according to the national statistics and 1222-4569, 1493-7346, and 1981-3649 kWh. It was determined that the collected usage data fell within the scope of the national statistics. However, the average energy usage values exhibited a difference of 4019,1875 , and $561 \mathrm{kWh}$ for gas usage and 103,119 , and $562 \mathrm{kWh}$ for electricity usage, respectively. 
TABle 15: National statistics on energy consumption data (kWh).

\begin{tabular}{|c|c|c|c|c|c|c|}
\hline \multicolumn{2}{|c|}{ Contents } & Average (kWh) & Min. value & Max. value & Distribution (\%) & Number of samples \\
\hline \multirow{3}{*}{ Type of building } & Detached house & 13328 & 2200 & 65505 & 37.62 & 948 \\
\hline & Multifamily house & 12808 & 2070 & 82053 & 18.41 & 464 \\
\hline & Small house & 12862 & 2570 & 142294 & 43.97 & 1108 \\
\hline \multirow{6}{*}{ Year of completion } & 1979 & 12696 & 2954 & 41471 & 8.25 & 208 \\
\hline & $1971-1979$ & 12874 & 2200 & 41134 & 9.56 & 241 \\
\hline & 1980-1989 & 12538 & 2419 & 142294 & 17.62 & 444 \\
\hline & 1990-1999 & 13053 & 2570 & 136606 & 38.81 & 978 \\
\hline & $2000-2009$ & 13550 & 2070 & 88926 & 22.94 & 578 \\
\hline & 2010 & 12989 & 3200 & 30559 & 2.82 & 71 \\
\hline \multirow{5}{*}{ Area } & $\sim 33 \mathrm{~m}^{2}$ & 11442 & 2070 & 31793 & 3.29 & 83 \\
\hline & $34-66 \mathrm{~m}^{2}$ & 11950 & 2200 & 65505 & 24.64 & 621 \\
\hline & $67-99 \mathrm{~m}^{2}$ & 13068 & 2991 & 88926 & 44.33 & 1117 \\
\hline & $100-132 \mathrm{~m}^{2}$ & 14001 & 2590 & 142294 & 23.41 & 590 \\
\hline & 132 & 14693 & 3211 & 32875 & 4.33 & 109 \\
\hline All & & 13027 & 2070 & 142294 & 100.00 & 2520 \\
\hline
\end{tabular}

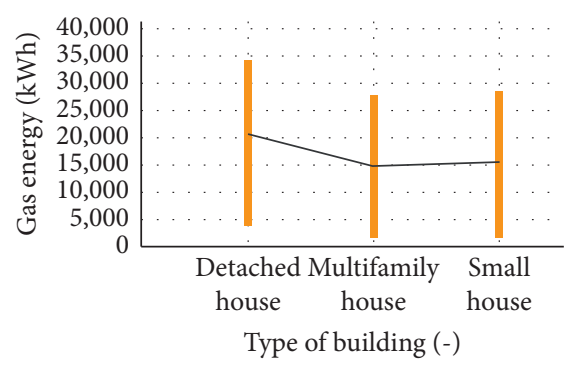

(a)

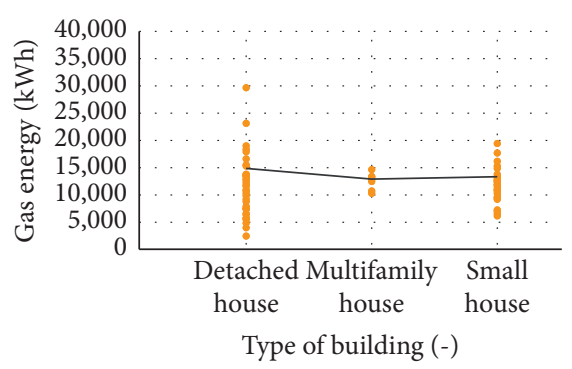

(d)

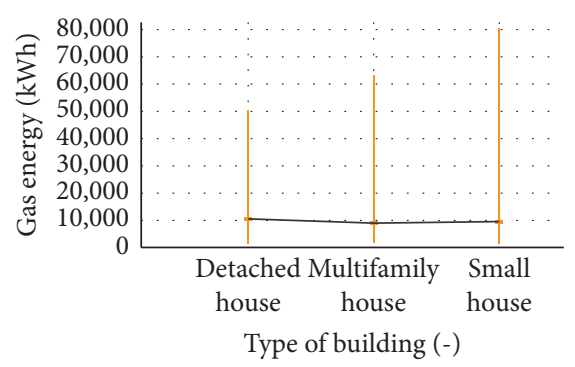

(g)

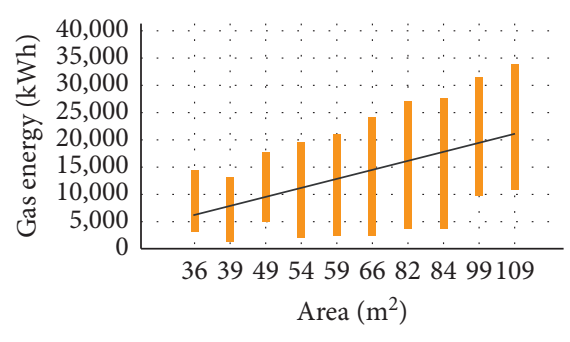

(b)

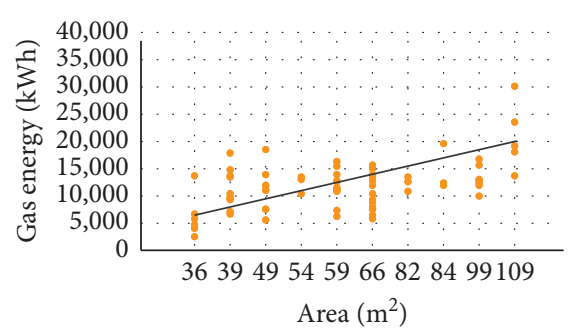

(e)

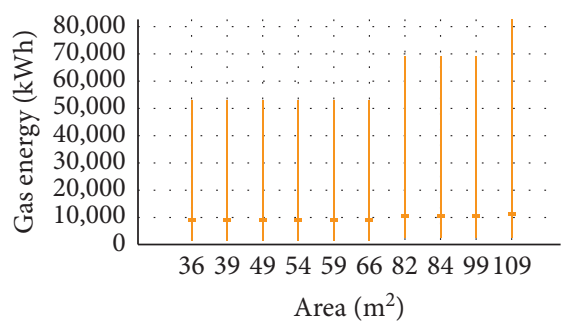

(h)

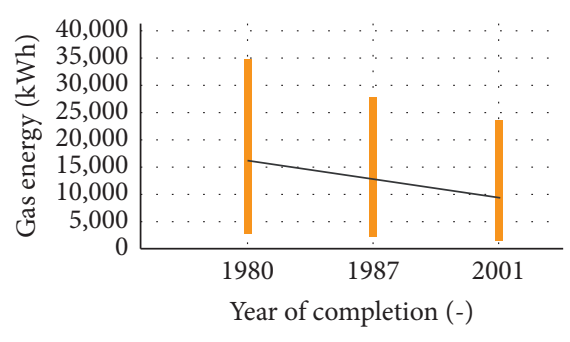

(c)

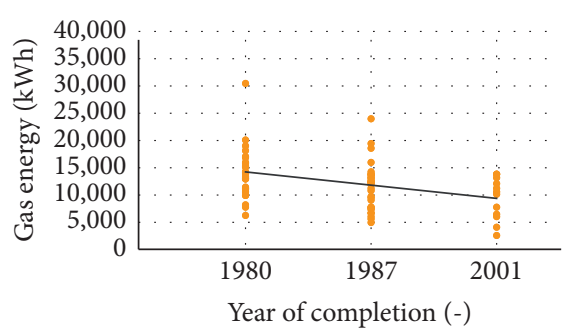

(f)

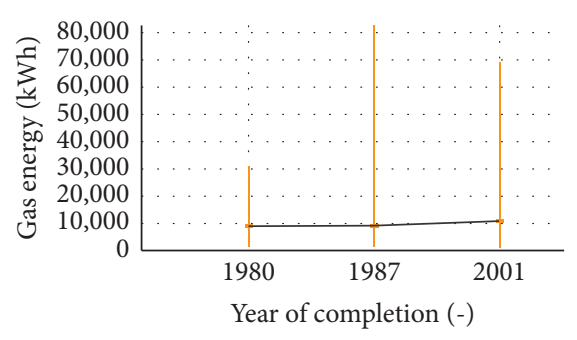

(i)

Figure 9: Analysis of gas energy usage patterns based on data. (a) Standard model: type of building. (b) Standard model: area. (c) Standard model: year of completion. (d) Collected data: type of building. (e) Collected data: area. (f) Collected data: year of completion. (g) National Statistics: type of building. (h) National Statistics: area. (i) National Statistics: year of completion.

In addition, the study verified energy usage according to the total floor area of buildings. The min-max gas usage ranges for the total floor areas of 34-66, 67-92, and
$100-132 \mathrm{~m}^{2}$ were found to be 1531-23 526, 2213-65 805, and 1916-105 $297 \mathrm{kWh}$ according to the national statistics and 2564-18 416, 9972-19435, and 13508-29636 kWh 


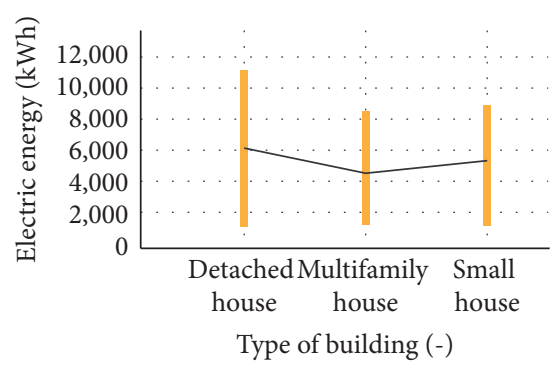

(a)

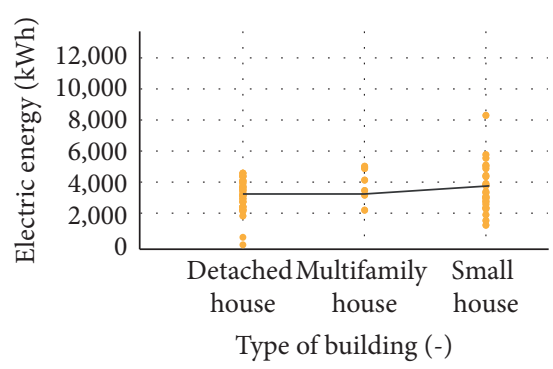

(d)

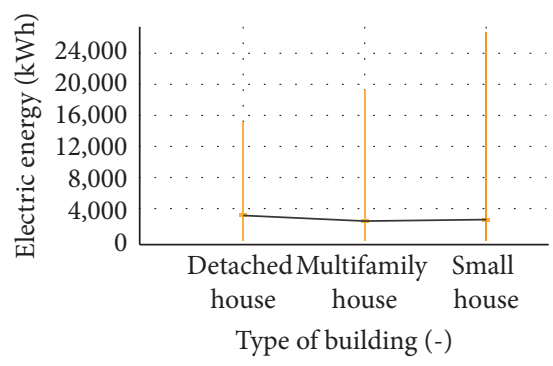

(g)

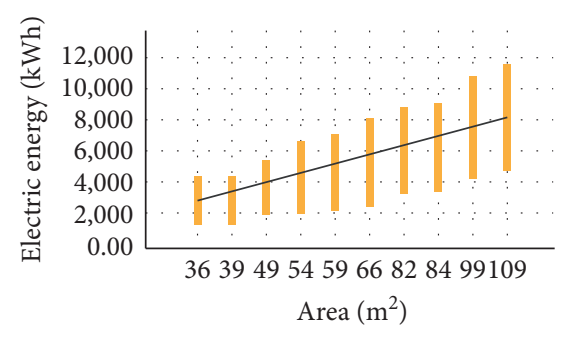

(b)

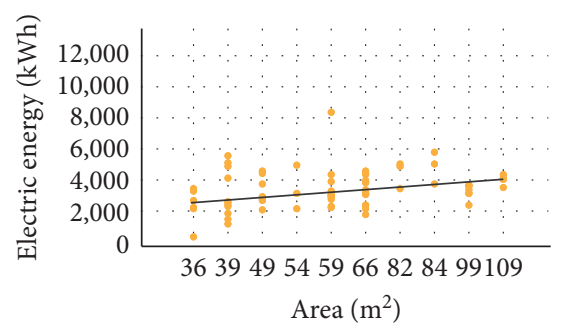

(e)

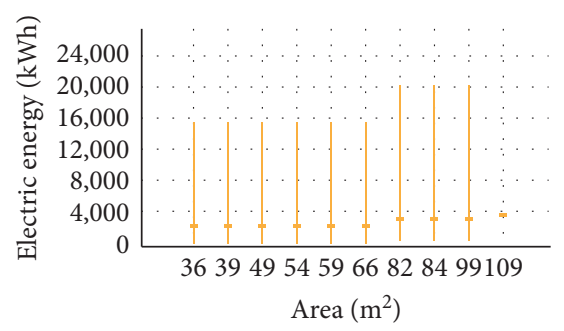

(h)

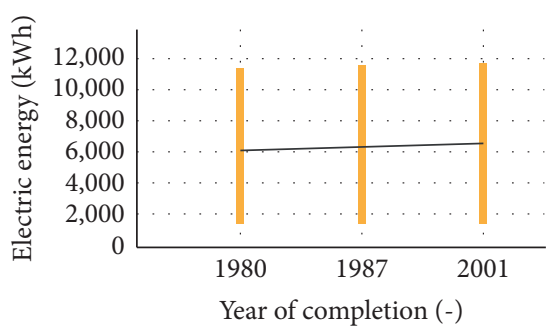

(c)

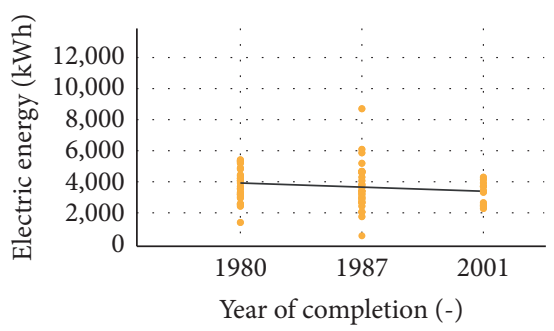

(f)

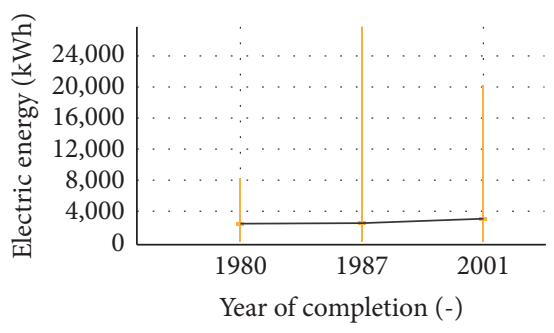

(i)

Figure 10: Analysis of electrical energy usage patterns based on data. (a) Standard model: type of building. (b) Standard model: area. (c) Standard model: year of completion. (d) Collected data: type of building. (e) Collected data: area. (f) Collected data: year of completion. (g) National Statistics: type of building. (h) National Statistics: area. (i) National Statistics: year of completion.

according to the collected energy usage. The min-max electricity usage ranges for the three different floor areas were 538-8266, 777-23120, and 498-27 377 kWh in the case of the national statistics and 1222-7346, 2254-5161, and $3219-3958 \mathrm{kWh}$ in the case of the collected energy usage. However, the average energy usage values exhibited a difference of 1688,3571 , and $10309 \mathrm{kWh}$ for gas usage and 105, 172 , and $10 \mathrm{kWh}$ for electricity usage, respectively.

The collected energy usage data were distributed within the national energy usage statistics data but with errors in the mean values. This is because the collected data had a smaller number of samples than the statistical data, and the energy usage in residential buildings varies according to the residents' schedules. However, the collected energy usage data were considered reliable as they fell within the scope of the national statistics.

\subsection{Energy Usage Analysis (National Statistics and Standard} Model). The standard model developed in this study was verified by comparing it with the national energy usage statistics data. Table 17 and Figure 12 show the results, and the details are given below.
The verification of energy usage by building type revealed that the min-max gas usage ranges for detached, multifamily, and row houses were 1628-48473, 1531-60 719, and 1901-105297 kWh, respectively, according to the national statistics. For the proposed standard model, the min-max gas usage ranges were 4085-33819, 1989-26 943, and 1989-27460 kWh. The min-max electricity usage ranges were $572-17031,538-21333$, and $668-36996 \mathrm{kWh}$ for the national statistics and 1562-10119, 1551.58-7655, and 1551-7991 kWh for the developed standard model. It was determined that the data for the proposed standard model were collected within the scope of the national statistics. However, the average energy usage values exhibited a difference of 7207,116 , and $254 \mathrm{kWh}$ for gas usage and 2307,867 , and $852 \mathrm{kWh}$ for electricity usage, respectively.

This study also verified energy usage according to the buildings' years of completion. The min-max gas usage values for 1980, 1987, and 2001 were found to be $1628-30439,1790-105297$, and 1901-101 $088 \mathrm{kWh}$ for the national statistics and 3156-33819, 2801-26900, and 1989-22 $481 \mathrm{kWh}$ for the developed standard model, respectively. The electricity usage values for 1980,1987 , and 
TABLE 16: Analysis of energy usage comparison: national statistics-usage (kWh).

\begin{tabular}{lcccccc}
\hline \multirow{2}{*}{$\begin{array}{l}\text { Contents } \\
\text { National statistics }\end{array}$} & Variable & Total of gas & & \multicolumn{2}{c}{ Total of electricity } \\
& & Average & Min. value & Max. value & Average & Min. value \\
Max. value
\end{tabular}

2001 were $572-10694,628-36996$, and $668-35517 \mathrm{kWh}$ for the national statistics and 1551-9706, 1602-10022, and $1606-10119 \mathrm{kWh}$ for the standard model. The study's data for the proposed standard model were determined to have been collected within the scope of the national statistics. However, the average energy usage values exhibited a difference of 3714,1487 , and $991 \mathrm{kWh}$ for gas usage and 1105 , 1274 , and $1179 \mathrm{kWh}$ for electricity usage, respectively.

In addition, we verified the energy usage according to the total floor area of buildings. The min-max gas usage values for the total floor area ranges of $34-66 \mathrm{~m}^{2}$, 67-92 $\mathrm{m}^{2}$, and $100-132 \mathrm{~m}^{2}$ were found to be $1531-23526$, 2213-65 805, and 1916-105297 kWh for the national statistics and 1990-23755, 4640-31336, and $11857-33819 \mathrm{kWh}$ for the collected energy usage, respectively. The min-max electricity usage values for the three total floor area ranges were 538-8266, 777-23 120, and $498-27377 \mathrm{kWh}$ for the national statistics and 1552-7090, 3227-9439, and 4517-10119kWh for the collected energy usage, respectively. However, the average energy usage values exhibited a difference of 131, 4489 , and $10691 \mathrm{kWh}$ for gas usage and 377, 2254, and $3411 \mathrm{kWh}$ for electricity usage, respectively.

The energy consumption of the standard model developed in this study was distributed within the national energy usage statistics data and, therefore, produced significant results but with errors in the mean values. In particular, there was a large error in detached houses. Owing to the characteristics of Korea, there are regulations on the total floor area and floor plan of multifamily and multi-household houses, but detached houses are difficult to regulate because they usually reflect a resident's preference, resulting in high variations and differences. The electricity usage according to the standard model was higher than that according to the national statistics because the input values of the developed model were calculated based on an assumption that electricity is used according to the schedule, but the actual usage depends on a resident's consumption characteristics, such as home appliance and air-conditioning usage.

\subsection{Verification Results of Standard Model and Collected} Energy Usage Data. This study developed specific variables and investigated them using the usage bills collected from 70 households. The study also performed simulations by matching the variables with the standard model's input values. Furthermore, the error rate and regression analyses were conducted. Figure 13 presents the verified results.

The gas usage and consumption verification results showed an error rate ranging from $0.69 \%$ to $44.58 \%$, with an average of $13.52 \%$. A correlation coefficient analysis identified the $R$ value as 0.9135 and the $R^{2}$ verification value as 0.8345 . Owing to Korea's climate characteristics, the heating (i.e., gas) energy is the main form of energy used in residential buildings in the winter season. Thus, valid results were derived.

The results of the electricity usage and demand verification indicated an error rate ranging from $0.29 \%$ to $122.58 \%$, with an average of $35 \%$. A correlation coefficient analysis identified the $R$ value as 0.4075 and the $R^{2}$ verification value as 0.1660 . The error rate was found to be high, while the $R$ verification result was the lowest for electricity usage. Electricity use is classified as cooling energy, lighting energy, and equipment energy use, but it is difficult to define it as a standard model because it relies largely on the consumption characteristics and behavior of residents. In particular, electrical energy is only a small amount of the total energy used in residential buildings. Moreover, since it is not used under the same conditions as in office buildings, there is a high error rate compared to gas consumption. 


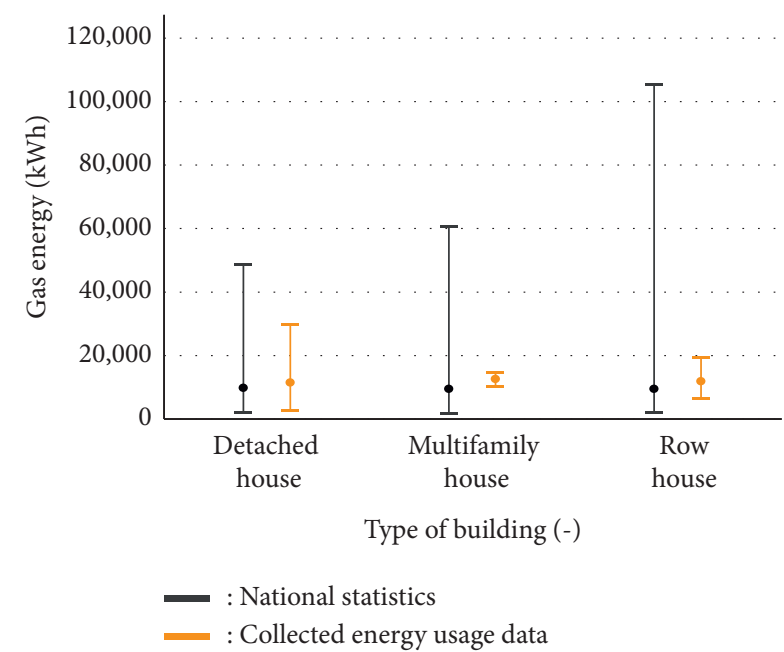

(a)

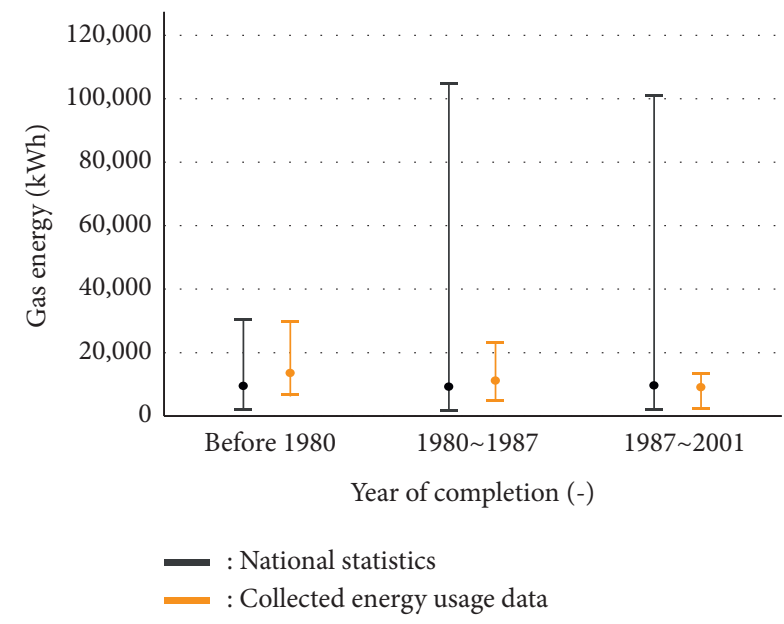

(c)

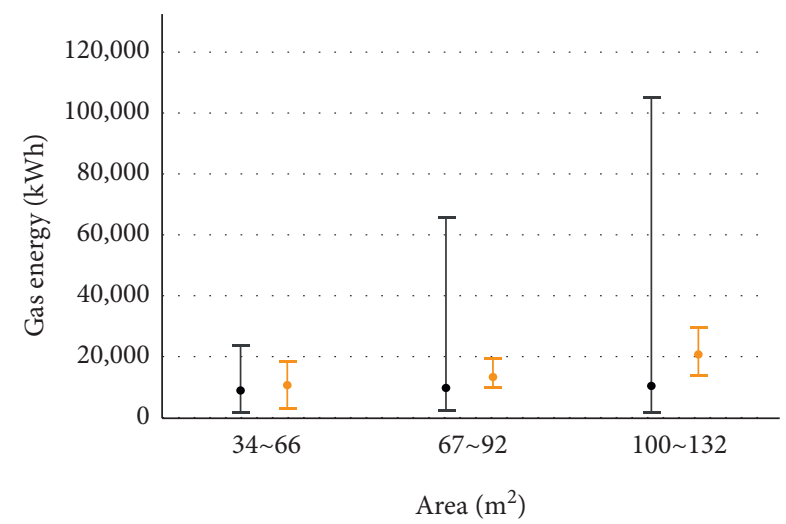

— : National statistics

(e)

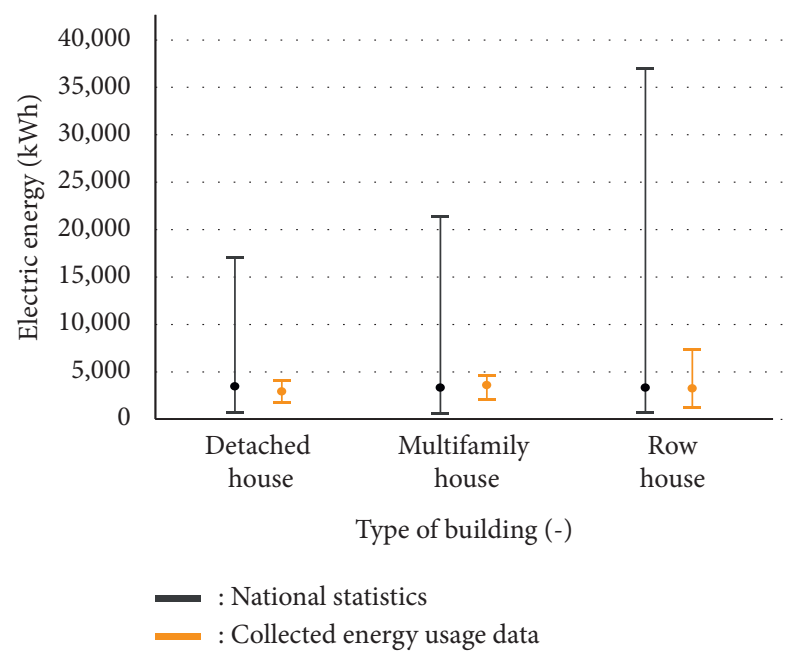

(b)

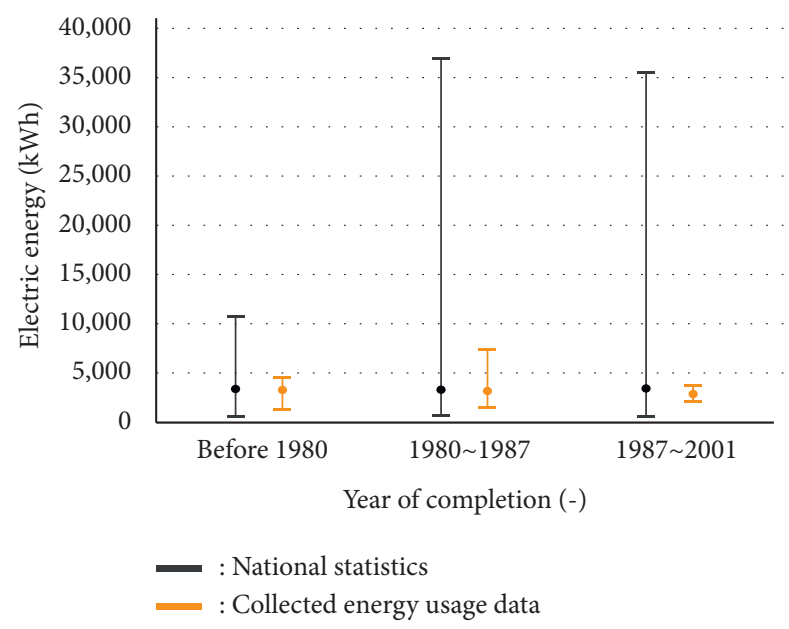

(d)

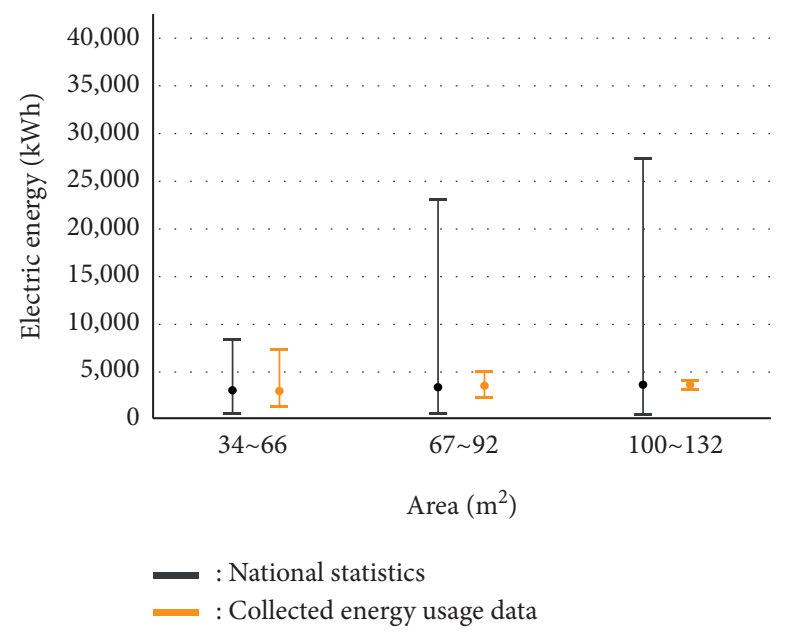

(f)

FIGURE 11: Comparative analysis of the energy usage range by standard model variables (National Statistics and Collected Energy Usage Data). (a) Gas energy: type of building. (b) Electric energy: type of building. (c) Gas energy: year of completion. (d) Electric energy: year of completion. (e) Gas energy: area. (f) Electric energy: area. 
TABLE 17: Analysis of energy usage comparison: national statistics-standard model (kWh).

\begin{tabular}{lcccccc}
\hline \multirow{2}{*}{$\begin{array}{l}\text { Contents } \\
\text { National statistics }\end{array}$} & Variable & Total of gas & & \multicolumn{2}{c}{ Total of electricity } \\
& & Average & Min. value & Max. value & Average & Min. value \\
Max. value
\end{tabular}

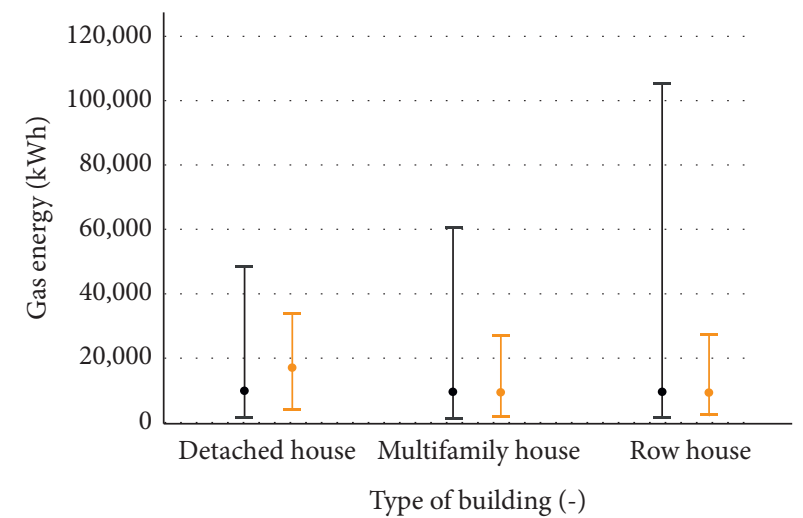

_ : National statistics

— : Standard model

(a)

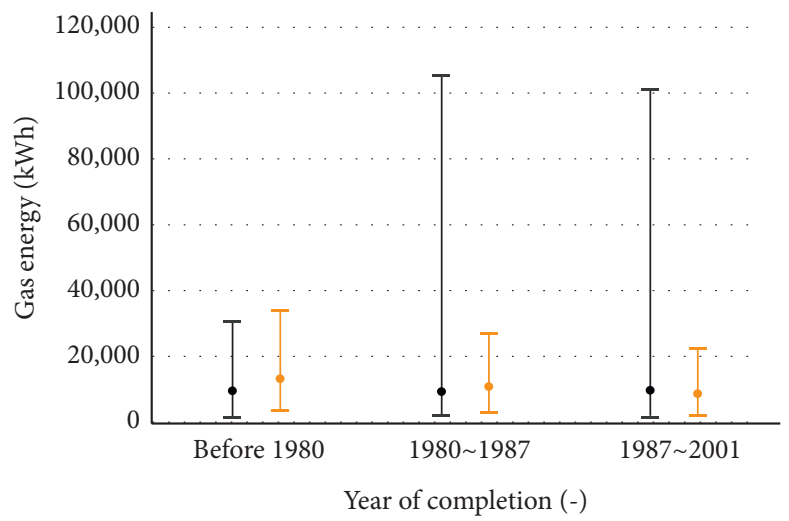

— : National statistics

- Standard model

(c)

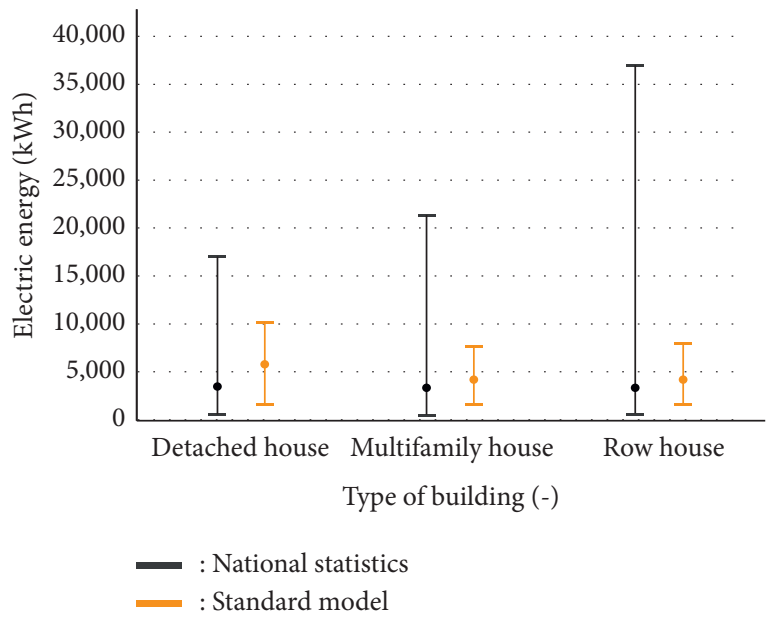

(b)

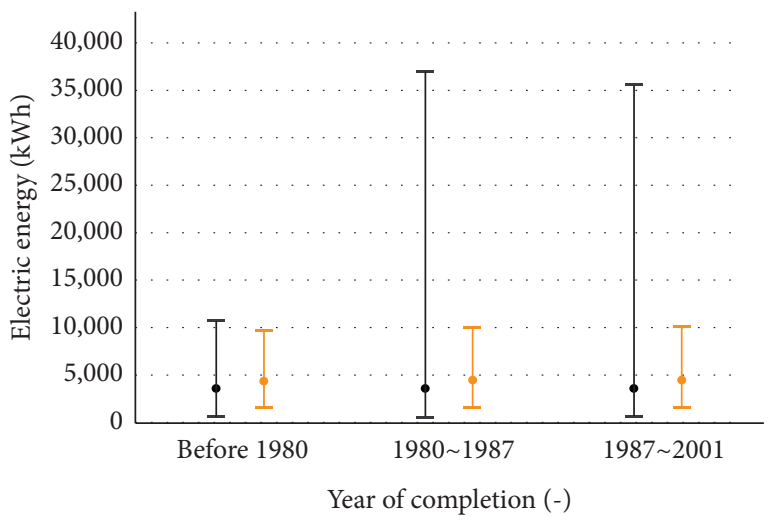

: National statistics

: Standard model

(d)

Figure 12: Continued. 


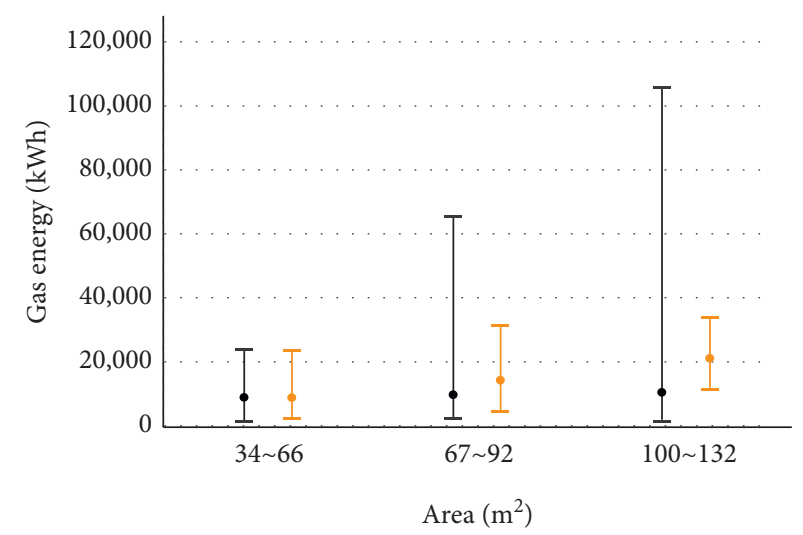

- National statistics Standard model

(e)

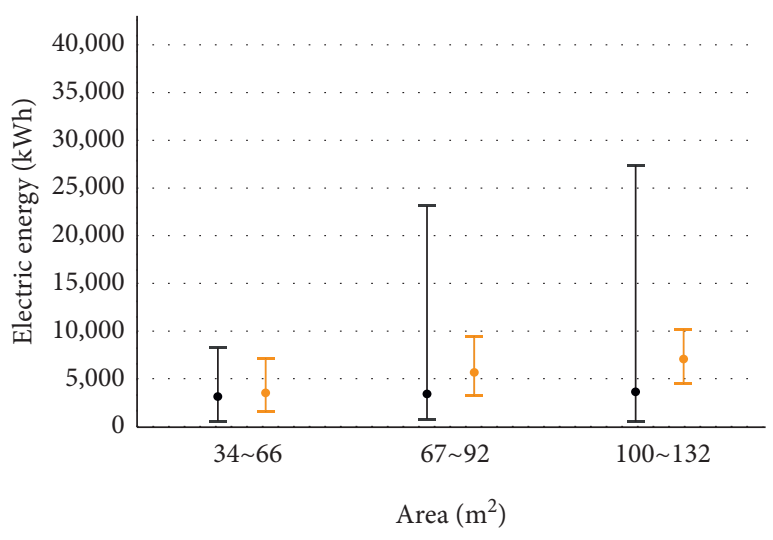

: National statistics

: Standard model

(f)

FIGURE 12: Comparative analysis of energy usage range by building variables (National statistics-Standard model). (a) Gas energy: type of building. (b) Electric energy: type of building. (c) Gas energy: year of completion. (d) Electric energy: year of completion. (e) Gas energy: area. (f) Electric energy: area.

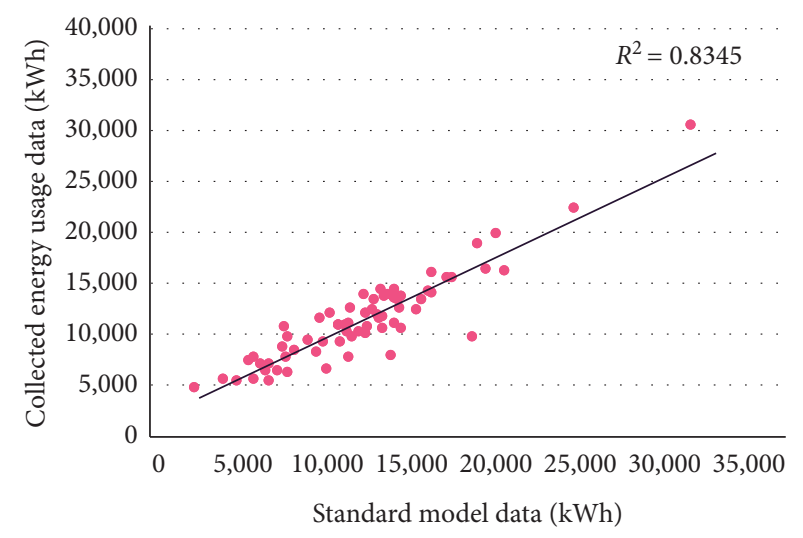

(a)

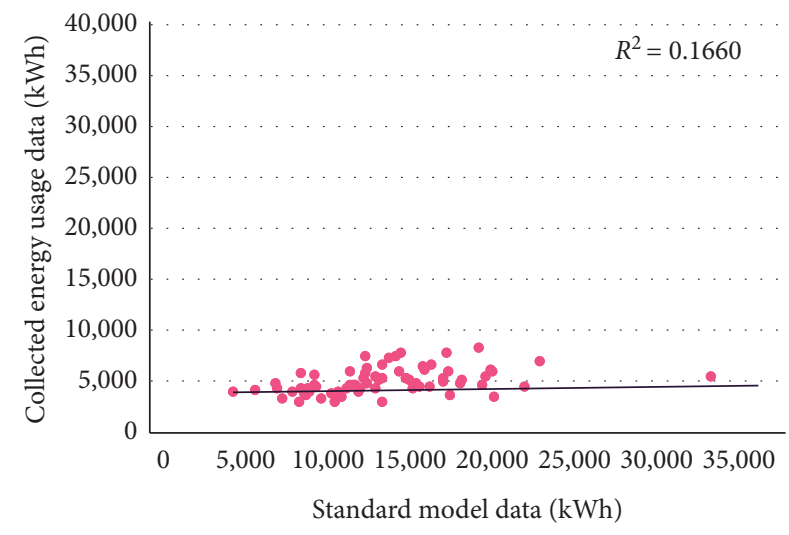

(b)

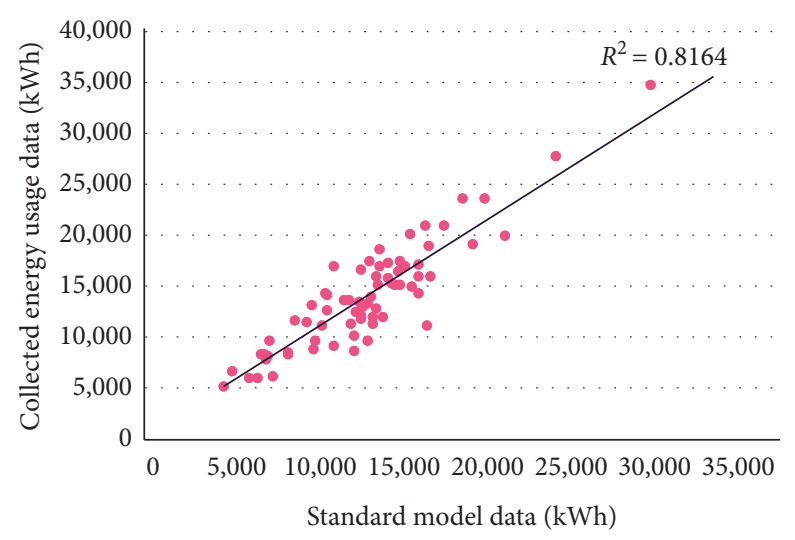

(c)

FIGURE 13: Analysis of standard model and collected energy usage data. (a) Analysis of gas energy consumption correlation. (b) Analysis of electric energy consumption correlation. (c) Analysis of total energy consumption correlation. 
The results of the sum of usage and consumption exhibited an average error rate of $12.67 \%$, with a minimum error rate of $0.11 \%$ and a maximum error rate of $41.07 \%$. A correlation coefficient analysis identified the $R$ value as 0.9035 and the $R^{2}$ verification value as 0.8164 . Since gas usage accounts for a large proportion of energy usage in residential buildings in Korea, the study's results were derived from the sum of gas and electrical energy usage.

\section{Discussion}

This study defined energy variables and input data based on statistical data from national institutions to propose a standard model for low-rise residential buildings in Korea. The energy consumption derived by evaluating energy performance using the proposed reference model was verified using the national energy usage statistics and actual collected usage data. The main findings and some limitations of this study are discussed in this section.

The energy usage collected according to the energy variables and energy range of the standard model fell within the range of the national energy usage statistics data, but with errors in the mean values. In the statistical data, the errors were caused by using the data derived through a sample survey of residential buildings with different total floor areas and operation schedules. However, the standard model developed in this study produced energy simulation results based on the reference total floor area, which resulted in errors. In addition, the residential building operation schedule in this study proposed a reference model using the data from reliable research institutes, but the equipment usage (HVAC, lighting, and other equipment) schedules produced different results depending on the users' characteristics, resulting in errors. The limitation of this study comes from considering only a standard occupancy schedule for working hours through national statistics without reflecting energy usage according to the age, income level, working hours, and use of equipment of occupants. Thus, additional energy consumption evaluations should be conducted by considering diverse occupancy schedules in the future.

The validation process using the actual usage of 70 households collected based on the standard model variables developed in this study presented valid analysis results for gas usage, but there was a large error in electricity usage. This is another limitation of this study, as it did not reflect the different operation schedules of cooling, lighting, and equipment caused by different consumption characteristics of actual residents. Various consumption schedules need to be defined according to energy usage to solve this problem. However, the final energy consumption was valid because the electricity usage does not account for a large portion of the total energy consumption in residential buildings compared to the gas usage, thus making the results significant as basic data for developing a standard model for lowrise residential buildings in Korea.

As such, additional studies should be conducted by including additional factors related to energy consumption patterns (income, household members, etc.) and analyzing annual consumption by usage to reduce the error rate of the standard model for low-rise residential buildings in Korea. Furthermore, this study was limited to the central region of Korea; thus, future studies should be conducted in various other regions of Korea to expand the applicability of the standard model.

\section{Conclusions}

This study developed a standard model for predicting energy usage in low-rise residential buildings in Korea and validated it through national energy usage statistics and actual building energy usage data. The final conclusions of this study are as follows:

(1) The variables of the developed standard model included building type, total floor area, width/ depth ratio, number of rooms, number of bathrooms, balcony type, insulation boundary condition, window-to-wall ratio, year of completion (heat transmission rate), building orientation, number of occupants, and occupancy schedule. A sensitivity analysis of energy consumption showed a significant correlation between the variables, with a significance level below 0.01 .

(2) The energy consumption pattern analysis showed that the standard model, national statistics, and collected energy usage data had similar patterns in terms of the building type (single house $>$ row house $>$ multifamily house), total floor area (energy usage increases with increasing total floor area), and year of completion $(1980>2000>2001)$.

(3) Both the standard model and the collected energy usage data fell within the range of the national energy usage statistics data, indicating that the standard model and the energy usage data were developed and collected effectively.

(4) Using the proposed standard model's variables, the input values from 70 households were collected and compared through a survey. Subsequently, the actual energy consumption and the energy usage values obtained via a simulation analysis were compared. The study found that the gas, electricity, and total energy usage amount error rates were $15.52 \%\left(R^{2}\right.$ : $0.8345), 35 \%\left(R^{2}: 0.1660\right)$, and $12.67 \%\left(R^{2}: 0.8164\right)$, respectively.

The validation of the developed standard model with the actual usage data showed that the significance of the total energy consumption was $80 \%$ or more, which indicated that the developed model was highly efficient in predicting the energy consumption of low-rise residential buildings in Korea. However, the limitations of this study lie in the facts that it did not reflect various energy consumption patterns in residential buildings and that its scope was limited only to the reference total floor area and the central region of Korea. As such, additional studies should be performed to reduce the error rate of the developed standard model by expanding the input 
data of various building schedules and energy factors, and by validating it through measuring and comparing various buildings.

\section{Data Availability}

The data used to support the findings of this study are included within the article.

\section{Conflicts of Interest}

The authors declare that they have no conflicts of interest.

\section{Acknowledgments}

This work was supported by the Korea Institute of Energy Technology Evaluation and Planning (KETEP) and the Ministry of Trade, Industry and Energy (MOTIE) of the Republic of Korea (Grant No. 20202020800360).

\section{References}

[1] Y. Chen, T. Hong, X. Luo, and B. Hooper, "Development of city buildings dataset for urban building energy modeling," Energy Build, vol. 183, pp. 252-265, 2018.

[2] J.-H. Woo and C. Menassa, "Virtual retrofit model for aging commercial buildings in a smart grid environment," Energy and Buildings, vol. 80, pp. 424-435, 2014.

[3] K. Kim, H. Lee, H. Jang, C. Park, and C. Choi, "Energy-saving performance of light shelves under the application of userawareness technology and light-dimming control," Sustainable Cities and Society, vol. 44, pp. 582-596, 2018.

[4] T. M. Uidhir, F. Rogan, M. Collins, J. Curtis, and B. P. Ó. Gallachóir, "Improving energy savings from a residential retrofit policy: a new model to inform better retrofit decisions," Energy and Buildings, vol. 209, Article ID 109656, 2020.

[5] J. Hong, G. Q. Shen, Y. Feng, W. S.-t. Lau, and C. Mao, "Greenhouse gas emissions during the construction phase of a building: a case study in China," Journal of Cleaner Production, vol. 103, pp. 249-259, 2015.

[6] Z. Wu, A. T. W. Yu, and L. Shen, "Investigating the determinants of contractor's construction and demolition waste management behavior in Mainland China," Waste Management, vol. 60, pp. 290-300, 2017.

[7] X. Wang, W. Feng, W. Cai, H. Ren, C. Ding, and N. Zhou, "Do residential building energy efficiency standards reduce energy consumption in China? - a data-driven method to validate the actual performance of building energy efficiency standards," Energy Policy, vol. 131, pp. 82-98, 2019.

[8] W. Wang, R. Zmeureanu, and H. Rivard, "Applying multiobjective genetic algorithms in green building design optimization," Building and Environment, vol. 40, no. 11, pp. 1512-1525, 2005.

[9] L. Gabrielli and A. G. Ruggeri, "Developing a model for energy retrofit in large building portfolios: energy assessment, optimization and uncertainty," Energy and Buildings, vol. 202, p. 109356, 2019.

[10] Z. Wu, H. Li, Y. Feng, X. Luo, and Q. Chen, "Developing a green building evaluation standard for interior decoration: a case study of China," Building and Environment, vol. 152, pp. 50-58, 2019.
[11] UNEP: (2018) https://www.unenvironment.org/exploretopics/ resource-efficiency/what-we-do/cities/sustainable-buildings.

[12] S. Oh and K. H. Kim, "Change-point modeling analysis for multi-residential buildings: a case study in South Korea," Energy and Buildings, vol. 214, Article ID 109901, 2020.

[13] Z. Wang and Y. Yang, "Features and influencing factors of carbon emissions indicators in the perspective of residential consumption: evidence from Beijing, China," Ecological Indicators, vol. 61, pp. 634-645, 2016.

[14] W. Qingqin and Z. Miao, "Introduction of the standard for energy efficient building evaluation," Sustainable Cities and Society, vol. 14, pp. 1-4, 2015.

[15] Ministry of Trade, Industry and Energy of Korea, Annual EndUse Energy Statistics, Ministry of Trade, Industry and Energy of Korea, Sejong City, Korea, 2019.

[16] B. Lee, Y. Jang, and J. Choi, "Multi-stage optimization and meta-model analysis with sequential parameter range adjustment for the low-energy house in Korea," Energy Building, vol. 214, Article ID 109873, 2019.

[17] H. Lee, K. Kim, J. Seo, and Y. Kim, "Effectiveness of a perforated light shelf for energy saving," Energy and Buildings, vol. 144, pp. 144-151, 2017.

[18] H. S. Suh and D. D. Kim, "Energy performance assessment towards nearly zero energy community buildings in South Korea," Sustainable Cities and Society, vol. 44, pp. 488-498, 2019.

[19] Korea Energy Economics Institute, A Study on Building Energy Policy Plan by Analyzing Factors of Energy Consumption in Residential Buildings, Korea Statistical Information Service, Sejong, Korea, 2017.

[20] U. K. Elinwa, J. E. Ogbeba, and O. P. Agboola, "Cleaner energy in Nigeria residential housing," Results Engineering, vol. 9, Article ID 100103, 2020.

[21] J. Jia and W. L. Lee, "Drivers of moderate increase in cooling energy use in residential buildings in Hong Kong," Energy and Buildings, vol. 125, pp. 19-26, 2016.

[22] M. Michael, L. Zhang, and X. Xia, "An optimal model for a building retrofit with LEED standard as reference protocol," Energy and Buildings, vol. 139, pp. 22-30, 2017.

[23] S. Goudarzi, M. H. Anisi, N. Kama, F. Doctor, S. A. Soleymani, and A. K. Sangaiah, "Predictive modelling of building energy consumption based on a hybrid nature-inspired optimization algorithm," Energy and Buildings, vol. 196, pp. 83-93, 2019.

[24] P. Moran, J. O’Connell, and J. Goggins, “Sustainable energy efficiency retrofits as residential buildings move towards nearly zero energy building (NZEB) standards," Energy and Buildings, vol. 211, Article ID 109816, 2020.

[25] T. Hong, Y. Chen, X. Luo, N. Luo, and S. H. Lee, "Ten questions on urban building energy modeling," Energy and Buildings, vol. 168, p. 106508, 2019.

[26] X.-C. Gui, Y.-T. Ma, S.-Q. Chen, and J. Ge, "The methodology of standard building selection for residential buildings in hot summer and cold winter zone of China based on architectural typology," Journal of Building Engineering, vol. 18, pp. 352359, 2018.

[27] E. Aydin and D. Brounen, "The impact of policy on residential energy consumption,” Energy, vol. 169, pp. 115-129, 2018.

[28] National Renewable Energy Laboratory, Department of Energy, Commercial Reference Building Models of the National Building Stock, National Renewable Energy Laboratory, Department of Energy, Golden, CO, USA, 2011.

[29] H. J. Kim and D. H. Seo, "A review on the definition methods of prototypical office building for energy analysis," Journal of 
the Architectural Institute of Korea Structure, vol. 34, pp. 103-111, 2018.

[30] L. Carnieletto, M. Ferrando, L. Teso et al., "Italian prototype building models for urban scale building performance simulation," Building and Environment, vol. 192, Article ID 107590, 2021.

[31] T. R. Khamma, Y. Zhang, S. Guerrier, and M. Boubekri, "Generalized additive models: an efficient method for shortterm energy prediction in office buildings," Energy, vol. 213, Article ID 118834, 2020.

[32] AHERAE, Standard 90.1 Prototype Building Models, 2016.

[33] A. P. Melo, M. J. Sorgato, and R. Lamberts, "Building energy performance assessment: comparison between ASHRAE standard 90.1 and Brazilian regulation," Energy and Buildings, vol. 70, pp. 372-383, 2014.

[34] International Organization for Standardization, Energy Performance of Buildings - Energy Needs for Heating and Cooling, Internal Temperatures and Sensible and Latent Heat Loads Part 1: Calculation Procedures, International Organization for Standardization, Geneva, Switzerland, 2017.

[35] International Organization for Standardization, Energy Performance of Buildings-Energy Needs for Heating and Cooling, Internal Temperatures and Sensible and Latent Heat Loads Part 2: Explanation and Justification of ISO 52016-1 and ISO 52017-1, International Organization for Standardization, Geneva, Switzerland, 2017.

[36] T. Zakula, M. Bagaric, N. Ferdelji, B. Milovanovic, S. Mudrinic, and K. Ritosa, "Comparison of dynamic simulations and the ISO 52016 standard for the assessment of building energy performance," Applied Energy, vol. 254, Article ID 113553, 2019.

[37] L. Mazzarella, R. Scoccia, P. Colombo, and M. Motta, "Improvement to EN ISO 52016-1:2017 hourly heat transfer through a wall assessment: the Italian National Annex," Energy and Buildings, vol. 210, Article ID 109758, 2020.

[38] S. Hu, D. Yan, S. Guo, Y. Cui, and B. Dong, "A survey on energy consumption and energy usage behavior of households and residential building in urban China," Energy and Buildings, vol. 148, pp. 366-378, 2017.

[39] F. Reda, P. Tuominen, Å. Hedman, and M. G. E. Ibrahim, "Low-energy residential buildings in New Borg El Arab: simulation and survey based energy assessment," Energy and Buildings, vol. 93, pp. 65-82, 2015.

[40] E. Mlecnik, T. Schütze, S. J. T. Jansen, G. de Vries, H. J. Visscher, and A. van Hal, "End-user experiences in nearly zero-energy houses," Energy and Buildings, vol. 49, pp. 471-478, 2012.

[41] F. Belaïd, D. Roubaud, and E. Galariotis, "Features of residential energy consumption: evidence from France using an innovative multilevel modelling approach," Energy Policy, vol. 125, pp. 277-285, 2019.

[42] Y. Zhang, X. Bai, and F. P. Mills, "Characterizing energyrelated occupant behavior in residential buildings: evidence from a survey in Beijing, China," Energy and Buildings, vol. 214, Article ID 109823, 2020.

[43] E. D. Fournier, F. Federico, E. Porse, and S. Pincetl, "Effects of building size growth on residential energy efficiency and conservation in California," Applied Energy, vol. 240, pp. 446-452, 2019.

[44] Y. You and S. Kim, "Revealing the mechanism of urban morphology affecting residential energy efficiency in Seoul, Korea," Sustainable Cities and Society, vol. 43, pp. 176-190, 2018.
[45] Korean Statistical Information Service, Housing by Type, Housing Units by Type of Housing Units, Total Floor Space and Number of Occupants, Sejong, Korea, 2017.

[46] Ministry of Land, Infrastructure and Transport, Republic of Korea, Seumter-Architecture Administration System, Sejong, Korea, 2017.

[47] J. W. Moon and J. Ahn, "Improving sustainability of everchanging building spaces affected by users' fickle taste: a focus on human comfort and energy use," Energy and Buildings, vol. 208, Article ID 109662, 2020.

[48] H. Lee, S. Chung, and J. Choi, "A study on the typological classification and characteristics of contemporary house plans," Journal of Building Engineering, vol. 10, no. 2, pp. 195-202, 1999.

[49] Korean Statistical Information Service, Data by type of house/ by total number of rooms, 2016.

[50] F. A. Chi, Y. Wang, R. Wang, G. Li, and C. Peng, "An investigation of optimal window-to-wall ratio based on changes in building orientations for traditional dwellings," Solar Energy, vol. 195, pp. 64-81, 2020.

[51] S. K. Alghoul, H. G. Rijabo, and M. E. Mashena, "Energy consumption in buildings: a correlation for the influence of window to wall ratio and window orientation in Tripoli, Libya," Journal of Building Engineering, vol. 11, pp. 82-86, 2017.

[52] Ministry of Land, "Infrastructure and Transport, Republic of Korea," Standard for Energy Saving Design of Building, vol. 1031, 2010.

[53] Korea Statistical Information Service, Types of Working Hours and Working Hours Per Week, Korea Statistical Information Service, Sejong, Korea, 2018.

[54] Statistics Korea, Analysis of Working Hour Statistics, Korea Statistical Information Service, Sejong, Korea, 2015.

[55] G. Jeon and S. Jung, "Comparative analysis of residential patterns of foreigners from rich and poor countries in Seoul," Sustainable Cities and Society, vol. 47, p. 101470, 2019.

[56] Korea Statistical Information Service, Types of Working Hours and Working Hours Per Week (Employees), Korea Statistical Information Service, Sejong, Korea, 2017.

[57] T. Østergård, R. L. Jensen, and S. E. Maagaard, "Early Building Design: informed decision-making by exploring multidimensional design space using sensitivity analysis," Energy and Buildings, vol. 142, pp. 8-22, 2017.

[58] F. Bre, A. S. Silva, E. Ghisi, and V. D. Fachinotti, "Residential building design optimisation using sensitivity analysis and genetic algorithm," Energy and Buildings, vol. 133, pp. 853866, 2016.

[59] W. Tian, "A review of sensitivity analysis methods in building energy analysis," Renewable and Sustainable Energy Reviews, vol. 20, pp. 411-419, 2013.

[60] M. H. Kristensen and S. Petersen, "Choosing the appropriate sensitivity analysis method for building energy model-based investigations," Energy and Buildings, vol. 130, pp. 166-176, 2016.

[61] M. Wang, J. Wright, A. Brownlee, and R. Buswell, "A comparison of approaches to stepwise regression on variables sensitivities in building simulation and analysis," Energy and Buildings, vol. 127, pp. 313-326, 2016.

[62] M. Shin and J. S. Haberl, Thermal Zoning for Building HVAC Design and Energy Simulation: A Literature Review, Korea Statistical Information Service, Sejong, Korea, 2019.

[63] F. E. Boafo, J.-G. Ahn, J.-T. Kim, and J.-H. Kim, "Computing thermal bridge of VIP in building retrofits using DesignBuilder," Energy Procedia, vol. 78, pp. 400-405, 2015. 
[64] A. Fathalian and H. Kargarsharifabad, "Actual validation of energy simulation and investigation of energy management strategies (Case Study: an office building in Semnan, Iran)," Case Studies in Thermal Engineering, vol. 12, pp. 510-516, 2018.

[65] Ministry of Trade, Industry and Energy, Regulation on Energy Efficiency, Korea Statistical Information Service, Sejong, Korea, 2011.

[66] Korea Land and Housing Corporation, A Study on the Development of Energy Simulation Tool for Green Remodeling Contractor, Korea Statistical Information Service, Sejong, Korea, 2018.

[67] Korea Energy Agency, Building Energy Efficiency Level Certification System Operation Regulations, Korea Statistical Information Service, Sejong, Korea, 2013.

[68] C. Srivastava, Z. Yang, and R. K. Jain, "Understanding the adoption and usage of data analytics and simulation among building energy management professionals: a nationwide survey," Building and Environment, vol. 157, pp. 139-164, 2019.

[69] V. T. Le and A. Pitts, "A survey on electrical appliance use and energy consumption in Vietnamese households: case study of Tuy Hoa city," Energy and Buildings, vol. 197, pp. 229-241, 2019.

[70] C. Wang, Y. Wu, X. Shi et al., "Dynamic occupant density models of commercial buildings for urban energy simulation," Building and Environment, vol. 169, Article ID 106549, 2020.

[71] R. Figueiredo, P. Nunes, M. J. N. Oliveira Panão, and M. C. Brito, "Country residential building stock electricity demand in future climate - Portuguese case study," Energy and Buildings, vol. 209, Article ID 109694, 2019. 